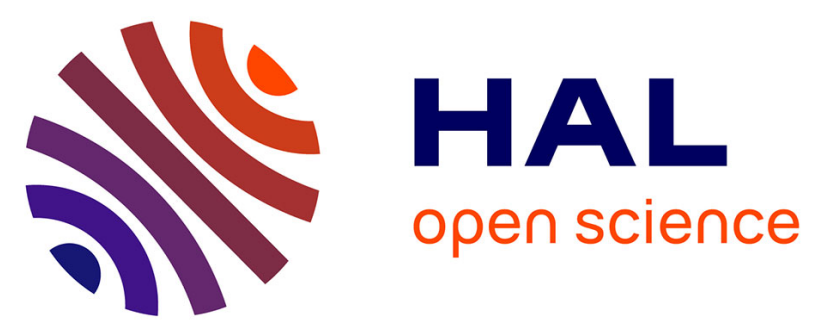

\title{
Selective transfer of Li-Al-rich phyllosilicate to metamorphic veins (Western Alps): Laser Induced Breakdown Spectroscopy (LIBS) compositional profiles and microstructural characterization
}

Anne Verlaguet, F. Brunet, B. Goffé, D. Menut, N. Findling, C. Poinssot, B. Huet

\section{To cite this version:}

Anne Verlaguet, F. Brunet, B. Goffé, D. Menut, N. Findling, et al.. Selective transfer of Li-Alrich phyllosilicate to metamorphic veins (Western Alps): Laser Induced Breakdown Spectroscopy (LIBS) compositional profiles and microstructural characterization. Journal of Geodynamics, 2016, 101, pp.51-72. 10.1016/j.jog.2016.05.011 . hal-01324880

\section{HAL Id: hal-01324880 \\ https: / hal.sorbonne-universite.fr/hal-01324880}

Submitted on 1 Jun 2016

HAL is a multi-disciplinary open access archive for the deposit and dissemination of scientific research documents, whether they are published or not. The documents may come from teaching and research institutions in France or abroad, or from public or private research centers.
L'archive ouverte pluridisciplinaire HAL, est destinée au dépôt et à la diffusion de documents scientifiques de niveau recherche, publiés ou non, émanant des établissements d'enseignement et de recherche français ou étrangers, des laboratoires publics ou privés. 


\title{
Selective transfer of Li-Al-rich phyllosilicate to metamorphic
}

\author{
veins (Western Alps): Laser Induced Breakdown Spectroscopy
}

(LIBS) compositional profiles and microstructural

\section{characterization}

A. Verlaguet ${ }^{1, *}$, F. Brunet ${ }^{2}$, B. Goffé ${ }^{3}$, D. Menut ${ }^{4}$, N. Findling ${ }^{2}$, C. Poinssot $^{5}$, B. Huet $^{6}$

${ }^{1}$ Sorbonne Universités, UPMC Univ Paris 06, CNRS, Institut des Sciences de la Terre de Paris (iSTeP), 4 place Jussieu, 75005 Paris, France; anne.verlaguet@ upmc.fr

2 Univ Grenoble Alpes, CNRS, ISTERRE, F-38041 Grenoble Cedex 9, France, fabrice.brunet@ujf-grenoble.fr; nathaniel.findling@ujf-grenoble.fr

3 Aix-Marseille Université, CNRS, IRD, CEREGE UMR34, 13545 Aix en Provence, France, goffe@cerege.fr

${ }^{4}$ CEA Saclay, DEN, Service de Recherches Métallurgiques Appliquées, 91191 Gif-surYvette France, denis.menut@cea.fr

5 Direction de l'Energie Nucléaire, Département RadioChimie \& Procédés, CEA Marcoule, 30207 BAGNOLS SUR CEZE, France; christophe.poinssot@cea.fr

${ }^{6}$ Department for Geodynamics and Sedimentology, University of Vienna, A-1090 Vienna, Austria; benjamin.huet@univie.ac.at

* Corresponding author:

Anne Verlaguet

Sorbonne Universités, UPMC, Univ Paris 06, iSTeP

Tour 46-0, E3, boite 129

4 place Jussieu 
75005 Paris

France

anne.verlaguet@upmc.fr

Phone: (33) 144273870

Fax: (33) 144275085 


\section{Graphical Abstract}

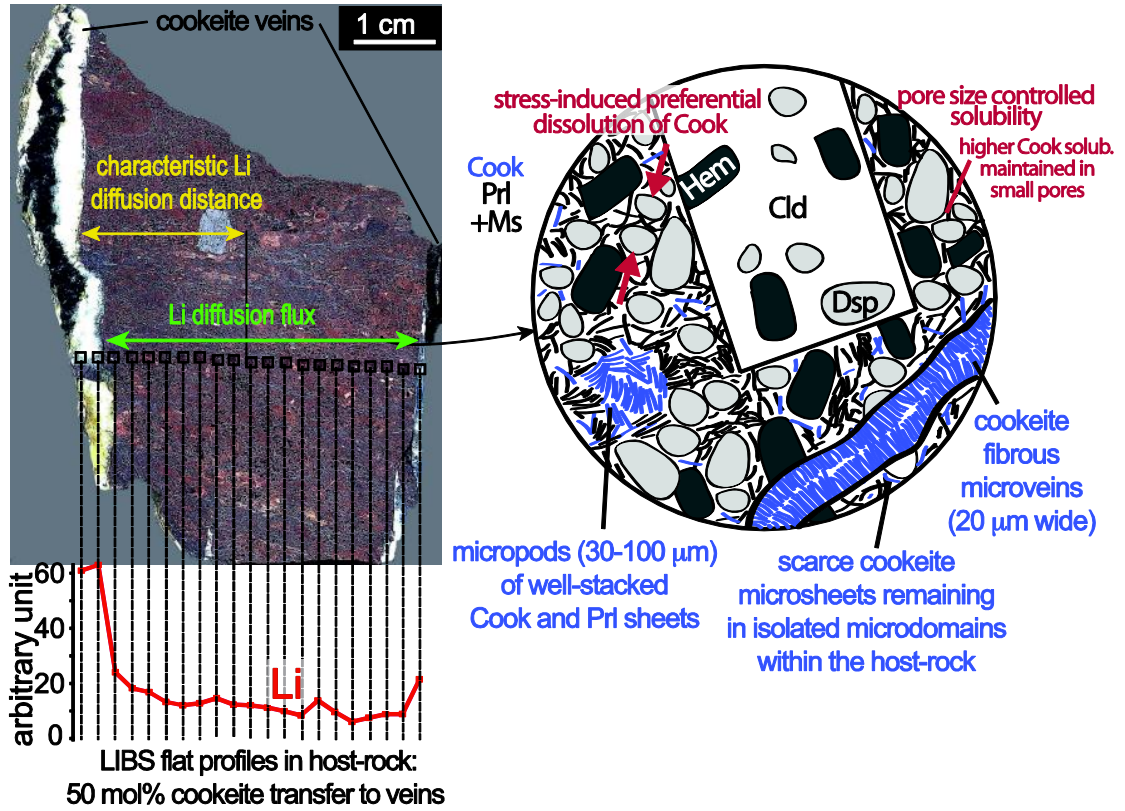




\section{Highlights}

- Cookeite was transferred to veins via a dissolution-transport-precipitation process

- LIBS profiles were performed between cookeite veins to study Li diffusive transfer

- $50 \%$ initial cookeite remains homogeneously distributed in host-rocks (flat profile)

- Efficient Li diffusion through the connected intergranular free fluid phase

- Mass transfer to veins may be interfacial energy driven or stress-induced 


\section{Abstract}

In convergent settings, fluid-rock interactions generally result in quartz and calcite preferential transfer to metamorphic veins in classical metamarls, while phyllosilicates tend to remain in the host-rock. However, the mechanisms responsible for such a selective mass transfer are poorly discussed in the literature. Here, we study Alpine metabauxites in which phyllosilicates (Li-Al-rich chlorite called cookeite, followed by pyrophyllite) were preferentially transferred to veins at blueschist peak P-T conditions, by a dissolutiondiffusion-precipitation process without any fluid infiltration or associated reaction. Cookeite fibrous en-echelon veins formed by extensional shear, and part of them evolved towards thicker fluid-filled veins with euhedral cookeite crystallization. We performed chemical profiles across host-rocks between successive cookeite veins, using Laser Induced Breakdown Spectroscopy (LIBS), associated to a microstructural study. Flat LIBS Li profiles show that about half of the initial cookeite remains homogeneously distributed in host-rocks, which suggests a diffusion distance of 2-4 $\mathrm{cm}$ for Li. The availability of an aqueous fluid during most of the metamorphic cycle is demonstrated here. A simple 1D reaction-diffusion model, assuming Li diffusion through a connected fluid-filled porosity network, is able to account for the observed lithium distribution assuming Li diffusion coefficients and mineral-water interaction rates consistent with literature values in fluid-bearing systems. Chemical potential gradients that drove phyllosilicate transfer to veins can be either interfacial energy driven (i.e., Ostwald ripening), the anhedral phyllosilicate microsheets maintaining high supersaturation levels in the small host-rock pores compared to veins, or stress-induced: phyllosilicates present the highest solubility variations with pressure in the Vanoise bauxites (contrary to quartz-bearing rocks), which may account for their unusual selective transfer to veins. Therefore, mineral solubility variation with pressure seems to be the chief controlling parameter for pressure-solution creep. Cookeite (over pyrophyllite) transfer to veins was 
favoured by faster $\mathrm{Li}$ diffusion (compared to $\mathrm{Si}$ and $\mathrm{Al}$ ). The shift from cookeite to pyrophyllite transfer, before host-rock cookeite-depletion, could reflect the onset of the retrograde P-T path, with pyrophyllite crystallization in response to P-T decrease. Lithium, which is a strategic element, was observed to preferentially migrate and segregate into veins during metamorphic processes, which may be of importance for exploration purposes.

Keywords: LIBS profiles; lithium diffusive transfer; interconnected fluid-filled porosity; fluid-rock interactions; Li-Al-rich phyllosilicate; metamorphic veins. 


\section{Introduction}

Large amounts of fluids are released in rocks during burial in convergent settings (subduction, collision), through successive dehydration reactions (e.g., Walther and Orville, 1982). The release of a free fluid phase in rocks has crucial effects on the scale of mass transfer processes and fluid-rock interactions (e.g., Boutoux et al, 2014a; John et al., 2012), but it also modifies the rock rheology and strongly influences the deformation processes (e.g., Bos and Spiers, 2000; Gueydan et al., 2004; and references therein). Moreover, there is a strong link between fluid-driven mass transfer and deformation mechanisms (e.g., Stunitz, 1998), mainly because the scale of fluid circulation and mass transfer is partly controlled by the size and connectivity of the deformation structures (e.g., Austrheim, 1987; Fisher et al., 1995; Penniston-Dorland et al., 2010). On the other hand, fluid-driven mass transfer from host-rock towards metamorphic veins, which is commonly observed during both burial and exhumation processes, can accommodate part of the rock deformation (e.g., Fisher et al., 1995; Yardley and Bottrell, 1992). Indeed, several generations of metamorphic veins are commonly observed in intermediate-grade mid-crustal rocks (Boutoux et al., 2014a; Gratier and Vialon, 1980; Wintsch and Yi, 2002) and HP/T metamorphic environments such as cold subduction zones (e.g., Widmer and Thompson, 2001). Veins are precious witnesses of fluidrock interactions and their structural and geochemical study (e.g., trace elements, isotopic signal, cathodoluminescence, fluid inclusions) can give clues about P-T, differential stress and strain conditions (e.g., Diamond and Tarantola, 2015; see Bons et al., 2012 for a review), as well as the nature, pathways, timing and scale of fluid circulation (e.g., Boutoux et al., 2014a; Marquer and Burkhard, 1992; Penniston-Dorland et al., 2010; Rolland et al., 2003; Spandler et al., 2011). There is thus a need to better constrain the potential driving forces controlling vein formation. 
A striking observation in metasandstones, metamarls and metapelitic rocks, is that quartz and/or calcite are preferentially (and almost exclusively) dissolved in the host-rock and reprecipitated in adjacent veins (e.g., Gratier and Vialon, 1980; Kirschner et al. 1995; Rutter, 1983; Tada and Siever, 1989), sometimes forming Ca- or Si-depleted haloes around veins (e.g., Fisher et al., 1995). In contrast, micas and clays tend to remain in the host-rock, and their presence is even observed to enhance quartz dissolution (i.e., catalytic effect), both in natural and experimental samples (Alcantar et al., 2003; Nenna and Aydin, 2011; Renard and Ortoleva, 1997; Renard et al., 1997). However, parameters controlling this "selective" mass transfer of quartz and calcite only, and concentration of phyllosilicates in the host-rock as dissolution residue, is poorly debated in the literature.

Here we study lenses of bauxitic rocks from the western Alps (Poinssot et al., 1997), in which several generations of metamorphic veins formed during Alpine blueschist metamorphism although these lenses remained isolated from external fluid infiltration (Verlaguet et al., 2011). Interestingly, in these quartz-free rocks, it is the phyllosilicates that were preferentially transferred to veins, via a dissolution-diffusion-precipitation process that occurred in the absence of any metamorphic reaction. Moreover, the vein minerals are Alrich, although $\mathrm{Al}$ is often considered as an almost immobile element (e.g., Carmichael, 1969), due to the low solubility of Al-bearing minerals in aqueous fluids. In subduction and orogenic environments, differential stresses are considered as the main driving force for mass transfer (Gratier and Guiguet, 1986; Rutter, 1976; Shimizu, 1995; see Wassmann and Stöckhert, 2013 for a review). Can stress-induced dissolution-precipitation be a viable mechanism to explain the transfer of Al-rich phyllosilicates to veins, in these rocks that exhibit very weak deformation structures? The striking differences in host-rock mineral sizes suggest that interfacial energy differences may also be a good candidate to explain such a selective mass transfer (e.g., Nakamura and Watson, 2001; Putnis and Mauthe, 2001). P-T variations along 
the metamorphic cycle may also be responsible for the selective transfer of silicates and Alrich phases towards fluid-filled open spaces (e.g., Goffé et al., 1987; Verlaguet et al., 2006; Verlaguet and Brunet, 2007).

Interestingly, the main mineral that crystallized in veins in these Alpine metabauxites is a lithium-bearing phyllosilicate, cookeite $\left(\mathrm{LiAl}_{5} \mathrm{Si}_{3} \mathrm{O}_{10}(\mathrm{OH})_{8}\right)$, which was highly transferred to veins at peak P-T conditions, via a dissolution - transport - precipitation process (Verlaguet et al., 2011). What were the modalities of lithium diffusive transfer and selective segregation into open fractures? $\mathrm{Li}$ is a mobile element used as a tracer of fluid-rock interactions and fluid pathways in subduction zones (e.g., Bebout, 2007; Penniston-Dorland, 2012). Li-chronometry was also recently developed, in which diffusion profiles of $\mathrm{Li}$ isotopes are used to constrain the duration of external fluid infiltration in rocks (John et al., 2012; Penniston-Dorland et al., 2010). Moreover, lithium is a strategic element used in multiple industrial products (e.g., batteries, aircraft alloys, weldments and weld joints, lithium ion conducting ceramics, ...), which drives active research for exploration and mining purposes, for example in lithium pegmatite ore bodies (e.g., Sweetapple and Tassios, 2015). There is thus a crucial need to better understand the natural processes of Li concentration, segregation, and mobility. The Vanoise metabauxites thus constitute an ideal case study to address these issues.

In order to constrain the modalities and controlling parameters of Li-bearing mineral diffusive transfer to veins in these Vanoise bauxites, we studied cookeite distribution in the host-rock around veins, to determine a potential depletion halo and evaluate the degree of cookeite concentration in veins. As Li is only hosted in cookeite, it can be used as a proxy for cookeite distribution. However, the challenge was to analyse in situ the distribution of $\mathrm{Li}$, a light element that cannot be measured with conventional X-ray analytical techniques, and over 10-20 cm long samples. We here present a new application of Laser Induced Breakdown Spectroscopy (LIBS), as a tool for performing in situ profiles of lithium (and other elements) 
distribution in host-rocks, between successive cookeite veins. Indeed, LIBS is an efficient technique for qualitative and semi-quantitative analysis of light elements like $\mathrm{Li}$, on large samples, and with rapid data acquisition for profiles and chemical maps (e.g., Fabre et al., 2002; Menut et al., 2003; Sweetapple and Tassios, 2015). Based on the analysis of optical emission spectroscopy of a laser-induced plasma, LIBS has been largely used for alloy analysis, but its calibration procedures for geological applications are still largely under development, in fields as varied as archaeology, gem minerals or Martian exploration (e.g., Maurice et al., 2012; McMillan et al., 2014; Rossi et al., 2014). LIBS is used here in an original way, along with a detailed microstructural characterization, in order to study mass transfer occurring during HP-LT metamorphism.

\section{Geological setting and previous work}

\subsection{Geological setting for alpine metabauxites}

In the western Alps, several outcrops of metabauxites are observed in the Briançonnais zone, in the external Alps, Ligurian Alps, Vanoise and Barrhorn (Fig. 1A; Goffé, 1982; Poinssot et al., 1997). Similar metabauxites also outcrop in similar stratigraphic position in the Apennines (Apuan Alps; Jolivet et al., 1998), Aegean sea (Feenstra et al., 2003) and in south-west Turkey (Rimmelé et al., 2003; Yalcin et al., 1993). These Triassic-to-Jurassic metabauxites form lens-shaped outcrops 1 to 15 meters thick, continuous over several meters, embedded in thick carbonate units. These laterite-type rocks correspond to continental sediments deposited in locally karstic Triassic dolomitic limestone, while the Briançonnais peninsula was temporarily emerged. These bauxites are overlapped by Dogger and/or Malm transgressive limestone units (Ellenberger, 1958; Goffé, 1982).

At the end of Eocene, the Briançonnais metabauxites were subducted into the Alpine convergence zone and underwent HP-LT metamorphism to various degrees (Fig. 1A; Jullien 
et al., 1996). In the internal French Alps, the Vanoise massif displays several outcrops of metabauxites metamorphosed under blueschist facies conditions $\left(360-375{ }^{\circ} \mathrm{C}, 1.1-1.4 \mathrm{GPa}\right.$; Fig. 1A; Bernard et al., 2007; Verlaguet et al., 2011). This study focuses on the western Vanoise metabauxites, because (1) they followed a cold anticlockwise retrograde path (Fig. 1) that preserved the high-pressure assemblage and (2) these rocks remained isolated from largescale fluid flow during metamorphism (i.e., closed system), as indicated by field and geochemical evidences (Verlaguet et al., 2011).

\subsection{External Alps bauxites: a reference frame for Vanoise metabauxites}

Only the bauxitic lenses situated in the external Alps were not metamorphosed: they just reached upper diagenetic conditions $\left(\sim 200{ }^{\circ} \mathrm{C}\right.$, Jaboyedoff and Thelin, 1996; Fig. 1A). As their chemical composition is very similar to that of the western Vanoise metabauxites (40-50 wt $\% \mathrm{Al}_{2} \mathrm{O}_{3}, 15-25$ wt $\% \mathrm{SiO}_{2}, 5-25$ wt $\% \mathrm{Fe}_{2} \mathrm{O}_{3}, 0.1-0.35$ wt $\% \mathrm{Li}_{2} \mathrm{O}$; Poinssot et al., 1997; Verlaguet et al., 2011), the external Alps bauxites can be considered, in first approximation, as the protolith of the western Vanoise metabauxites. The external Alps samples from the Pointe de Dréveneuse (Swiss Alps) are mainly composed of clay minerals (kaolinite, smectite, illite), Al-hydroxides (diaspore and/or boehmite), Al-berthierine, hematite and Ti-oxides. Modal calculations suggest that lithium is most likely contained in swinefordite-type Li-rich smectite (Verlaguet et al., 2011). These bauxites do not show any deformation and contain rounded or elongate pisoids (mainly filled with clay minerals and Al-hydroxides), typical of karstic deposits (Bardossy, 1982).

\subsection{Fluid release along the prograde P-T path in western Vanoise metabauxites}

In western Vanoise, although the whole carbonate-metabauxite formation is affected by $\mathrm{km}$-scale folds, at the outcrop scale the deformation is minimal, as shown by the absence of 
schistosity and the general preservation of the sedimentary pisoids, somewhat more elongate. Samples from the Aiguille du Rateau are composed of chloritoid (15-45 vol\%), diaspore (1540 vol\%), pyrophyllite (15-30 vol\%), cookeite (Li-rich aluminous chlorite, 5-15 vol\%) and hematite (1-15 vol\%), with minor amounts of rutile (2-5 vol\%), muscovite and paragonite (1$4 \mathrm{vol} \%)$. The range of calculated modal compositions reflects important lateral variations in metabauxite chemical composition. Microstructural observations show that this paragenesis corresponds to the peak metamorphic assemblage. The sole retrograde mineral in these rocks is scarce chlorite, only observed in late veins (Fig. 1B; Verlaguet et al., 2011).

By comparing the chemical composition and mineralogy of the western Vanoise metabauxites with that of their protolith (external Alps bauxites), Verlaguet et al. (2011) inferred that a large amount of fluid $(\sim 13$ vol\%) was liberated by successive dehydration reactions during Alpine metamorphism: about 20-30\% of this fluid may have been released upon clay mineral progressive breakdown (up to $\sim 250-300^{\circ} \mathrm{C}$ ), while $70-80 \%$ were liberated by the successive reactions of pyrophyllite and chloritoid formation $\left(\sim 320\right.$ and $340{ }^{\circ} \mathrm{C}$ respectively), before the rock underwent the peak metamorphic P-T conditions (Fig. 1B). Part of this internally-derived fluid remained in the bauxite lenses during most of the metamorphic cycle, and promoted the opening of fluid-filled open spaces in which various Al-rich minerals crystallized with euhedral morphology.

\subsection{Chronology of dehydration reactions vs mass transfer towards metamorphic veins}

The chronology of three successive vein generations could be determined using crosscutting relationships (Fig. 1B; Verlaguet et al., 2011): (1) chloritoid (+/- pyrophyllite) veins, which are synchronous with the chloritoid-in reaction in the rock, (2) cookeite veins showing en-echelon structures or thicker veins, (3) chlorite veins formed either as a second growth generation in the median plane of previous cookeite veins or as newly formed veins, 
and corresponding to the incipient retrograde destabilisation of chloritoid, (3bis) numerous pyrophyllite veins always forming a second growth generation in the median plane of cookeite veins, sometimes with chlorite. Although both pyrophyllite and chlorite veins postdate cookeite veins, the chronology of pyrophyllite versus chlorite veins remains uncertain: replacement patterns of both chlorite by pyrophyllite and the reverse in the same vein suggests that pyrophyllite and chlorite could in fact be coeval. Based on their mineralogical and textural features, the metabauxite veins can be classified into two different vein types, implying different formation mechanisms: (1) some veins are filled with newly formed products of either prograde (chloritoid) or retrograde (chlorite) metamorphic reactions; in this case, fluid-filled open spaces seem to offer energetically favourable nucleation and growth sites; (2) veins filled with a mineral (cookeite, pyrophyllite) that had already crystallized in the host-rock prior to the vein formation: the vein infill minerals were transferred from host-rock to veins through the fluid, in a dissolution-transport-precipitation process, which driving forces still need to be further constrained (Verlaguet et al., 2011).

\section{Description and chronology of the cookeite and pyrophyllite veins}

In western Vanoise metabauxites, cookeite veins (Figs. 1B; 2A, B, C) are widespread but heterogeneously distributed: they locally form numerous straight and roughly parallel structures, spaced by about 3-7 cm, whereas some samples are devoid of cookeite veins. Cookeite fills either small en-echelon veins $(0.05-1 \mathrm{~mm}$ wide, $1-3 \mathrm{~cm}$ long; Figs. 1B, 2D) or wider veins $(0.2-1.2 \mathrm{~cm}$ wide, 3-30 $\mathrm{cm}$ long; Figs. 1B, 2A, E), the largest exhibiting a later generation of euhedral pyrophyllite (Figs. 2B, C, F) and/or chlorite (Fig. 1B) in their centre. In any case, the vein walls and terminations are covered with micrometric cookeite fibres that grew symmetrically from both vein walls (generation 1, Figs. 2A-C, E). These fibres are generally perpendicular to the vein walls (Figs. 2A-C, E), yet in some cases, they grew with an oblique (or varying) direction and thus recorded the relative shearing movement of the vein 
walls during their growth (Figs. 2D, E). This fibrous generation has a constant width of 0.3-1 mm (Figs. 2A-F), independent of the vein width. While en-echelon veins only contain this fibrous cookeite (generation 1, Fig. 2D), wider veins exhibit a second generation of euhedral cookeite sheets organised in fan-shaped structures, seeded on the fibres and growing symmetrically from both fibrous vein walls towards the median plane (syntaxial growth; generation 2, Figs. 2A-C, E-F). Fragments of the host-rock, pulled out during the vein formation, are frequently observed in these veins (Figs. 1B; 2A). Wide cookeite veins often exhibit multiple fibrous terminations (Figs. 2B, C). Cookeite has the same composition in both host-rocks and veins, very close to the pure end-member composition $\left(\mathrm{LiAl}_{5} \mathrm{Si}_{3} \mathrm{O}_{10}(\mathrm{OH})_{8}\right.$, di-trioctahedral chlorite; Goffé, 1977; Vidal and Goffé, 1991). However, cookeite morphology is very different in the host-rock, where cookeite forms micrometric fibres (1-10 $\mu \mathrm{m}$ long, $<1 \mu \mathrm{m}$ wide), either isolated and dispersed among chloritoid ( 20-100 $\mathrm{x} 100-400 \mu \mathrm{m})$ and diaspore ( $20 \mu \mathrm{m}$ diameter) crystals, or associated to nicely stacked pyrophyllite sheets $(10-30 \mu \mathrm{m}$ large pods $)$. Locally, fibrous cookeite microveins $(<20 \mu \mathrm{m}$ wide; Figs. 2G, H) that seem to have aborted, as well as $30-100 \mu \mathrm{m}$ large pods of stacked cookeite sheets can be observed in the host-rock (Fig. 2H). Cookeite is also locally concentrated, with other Al-bearing phases, in pisoids.

Cookeite veins clearly crosscut and thus postdate both chloritoid crystals in the host-rock (Fig. 2G) and chloritoid veins, which are synchronous with the chloritoid-in reaction (reaction c, point 3 on Fig. 1B). On the other hand, the cookeite-in reaction took place before (i.e., at lower temperature on the prograde path, curve 1 on Fig. 1B) the chloritoid-in reaction according to thermodynamic modelling, which is supported by scarce cookeite inclusions in chloritoid crystals. Moreover, cookeite is part of the peak metamorphic paragenesis, meaning that cookeite cannot be the result of a retrograde reaction. All these observations clearly show that cookeite in veins cannot be the result of the cookeite-in reaction or any other 
metamorphic reaction, as concluded by Verlaguet et al. (2011). Therefore, cookeite first formed in the rock matrix (i.e., before chloritoid vein formation) and was later (i.e., after chloritoid vein formation) transferred from host-rock to opening veins through the remaining fluid.

Pyrophyllite always grew as a later generation in the median plane of the largest cookeite veins, which implies that pyrophyllite veins always postdate cookeite veins (Figs. 1B; 2 B, C, F). Pyrophyllite forms a unique generation of euhedral sheets grown into vermicular structures in all directions (generation 3; Figs. 2B, C, F). Pyrophyllite is one of the most abundant minerals in the Vanoise bauxites, and can thus form thicker fillings $(0.1-5 \mathrm{~cm}$ wide; Figs. 1B; 2 B, C, F) than the cookeite generation. Sheared fibrous pyrophyllite micro-veins (0.5 mm width), recalling cookeite features, were observed in one sample, which is interestingly devoid of cookeite veins (Rat6V1; Fig. 2I). Note that all the phyllosilicates (i.e., cookeite, pyrophyllite $+/$ - muscovite and paragonite) form isolated microsheets in the hostrock, and therefore present a very different morphology compared to other minerals (i.e., chloritoid and diaspore), which rather exhibit euhedral morphologies. Pyrophyllite veins clearly postdate the pyrophyllite-in reaction (curve 2 on Fig. 1B) and pyrophyllite is part of the peak metamorphic assemblage (i.e., no pyrophyllite-out reaction crossed). Therefore, similarly to cookeite, pyrophyllite first grew in the host-rock and was later transferred to veins.

\section{Sampling strategy and analytical approach}

\subsection{Analytical strategy}

Cookeite distribution in the host-rock, between two successive cookeite veins, could give insights into lithium mobility and modalities of its transfer to veins, as well as better constraints on the driving forces that led to cookeite selective dissolution from the host-rock, 
transport and precipitation into veins. However, because most elements are partitioned between several mineral phases, quantifying the distribution of minerals in a rock is often challenging. In these metabauxites, as lithium is only hosted in cookeite, Li distribution in the host-rock can be used as a good proxy for cookeite distribution. However, lithium is a light element that cannot be analysed with classical in situ X-ray techniques such as electronic microprobe or scanning electron microscopy. Here we used Laser Induced Breakdown Spectroscopy (LIBS) to analyse the distribution of Li and other elements in the metabauxites. LIBS is an atomic emission spectroscopy technique allowing analysis of most of the periodic table elements, based on the spectroscopic analysis of elemental characteristic spectra emitted from a plasma, generated by a high-energy laser beam focused on a sample (solid, liquid or gas). Widely used for alloy characterization, LIBS development for geological applications was highly driven by its selection as a major chemical tool to equip the Martian rover Curiosity (ChemCam Instrument, e.g., Fabre et al., 2011; Sallé et al., 2006; Sautter et al., 2014). Here, LIBS was chosen because in addition to be a powerful technique for the analysis of light elements like Li (Fabre et al., 2002; Rossi et al., 2014), it allows (1) the analysis of large samples that can be thin sections or thick rock slices, necessary here as the distance separating two successive veins was up to $7 \mathrm{~cm}$, with almost no specific sample preparation nor sample destruction, (2) a very rapid data acquisition of 20 analysis points per second, (3) the analysis of low-concentration elements like $\mathrm{Li}\left(0.1-0.35 \mathrm{wt} \% \mathrm{Li}_{2} \mathrm{O}\right.$ in the Vanoise bauxites) owing to detection limits as low as 1-3 ppm for Li (Table 1). LIBS was also shown to be an effective tool for mapping various element (Menut et al., 2003), including Li (Sweetapple and Tassios, 2015) in minerals.

In the Vanoise bauxites, mineral grain size is very heterogeneous (i.e., chloritoid crystals up to $400 \mu \mathrm{m}$ long vs $1-10 \mu \mathrm{m}$ long cookeite and pyrophyllite sheets). Therefore, LIBS laser spots of about $10 \mu \mathrm{m}$ would mainly reflect the mineral distribution in the rock. As the aim of 
this study is to illustrate cookeite distribution in host-rocks between cookeite veins, elemental profiles of $1 \mathrm{~mm}^{2}$ LIBS chemical maps (i.e., larger than the chloritoid grain size to overcome mineral distribution effects) were performed between two successive cookeite veins on 4 samples from the western Vanoise metabauxites. Linear LIBS profiles (10 $\mu \mathrm{m}$ spots every 10 $\mu \mathrm{m})$ were also performed across en-echelon cookeite veins. To determine the sedimentary distribution of lithium in the bauxite protolith (i.e., external Alps bauxites), and infer the extent of its redistribution during metamorphism, profiles were also performed on three samples from the external Alps bauxites.

The major drawback of the LIBS is however that the analyses cannot be easily and directly quantified, mainly due to both physical and chemical matrix effects (see Appendix A). Therefore, the quantification of the lithium amount in the host-rock between cookeite veins was determined independently, by whole-rock chemical analyses (ICP-OES). Samples free of cookeite veins were also analysed to test the influence of the rock chemistry on cookeite vein development.

Note that pyrophyllite vein formation also required a selective dissolution, transport and precipitation in the absence of any metamorphic reaction, so the distribution of pyrophyllite in the rock may also give clues on the mass transfer driving forces. However, although both Al and $\mathrm{Si}$ could be analysed by LIBS, these elements are partitioned between most of the Vanoise bauxite minerals, and as LIBS analyses cannot be properly quantified, it was not possible to retrieve pyrophyllite distribution.

\subsection{Analytical techniques}

\subsubsection{Chemical analyses}

Whole-rock chemical analyses were performed at the SARM (CRPG Nancy, France) from ground bauxitic samples. After fusion with $\mathrm{LiBO}_{3}$ and dissolution in $\mathrm{HNO}_{3}$, major elements 
were analysed by ICP-OES. $\mathrm{Li}_{2} \mathrm{O}$ was analysed by flame atomic absorption, after fusion with $\mathrm{Na}_{2} \mathrm{CO}_{3}$ and dissolution in $\mathrm{H}_{3} \mathrm{BO}_{3}$. The loss on ignition was measured.

\subsubsection{LIBS compositional profiles}

\subsubsection{LIBS instrument}

LIBS analytical methods and principles have been extensively discussed in several papers (e.g., Moenke-Blankenburg, 1989; Sallé et al., 2006). Laser Induced Breakdown Spectroscopy analyses were performed at CEA Saclay (DEN). The LIBS instrument consists of a modified optical microscope equipped with a laser (ablation source) and a high-precision XY stepper motor (ETEL Motion Technology, adapted for heavy samples, precision $<10 \%$ of displacement step), coupled to two optical spectrometers allowing analysis of the plasma emission signal, collected at the sample surface by optical fibres (see Menut et al., 2003 for a scheme of the setup). A Nd-YAG laser (Minilite II Continuum, $266 \mathrm{~nm}$, energy of $4 \mathrm{~mJ}$ per pulse) beam is focused onto the sample surface by a refractory microscope objective, generating a plasma during the laser-matter interaction. The typical emission lines of the elements present in the plasma are guided by optical fibres $(3 \mathrm{~m}$ long, aperture 0.22 , core diameter $1000 \mu \mathrm{m}$ ) towards two Czerny Turner spectrometers (spectral range of $20 \mathrm{~nm}$, spectral resolution of $0.065 \mathrm{~nm}, 1200$ groove/mm grating) equipped with a pulsed intensified

CCD camera (ICCD Princeton Instruments). An adjustable time delay (DG535, Stanford Research Systems) filters the continuous emission occurring in the first tens of nanoseconds after the laser shot in order to optimize the signal-to-background noise ratio. The optimal delay in our case was $100 \mathrm{~ns}$ for a temporal window of $4 \mu$ s. Both laser and ICCD are slaved to the XY driver that governs all the experimental setup, through the software Winspec/32. An argon flux is sweeping the sample surface to isolate the plasma, and thus improves the plasma intensity and reduces self-absorption processes (Sallé et al., 2006). 


\subsubsection{Operating conditions for the Vanoise bauxites}

For the Vanoise bauxites, the challenge was to analyse most major elements (i.e., Al, Si, $\mathrm{Fe}, \mathrm{Mg}$ and in particular Li) on two spectrometers with each a $20 \mathrm{~nm}$ spectral range. Priority was given to $\mathrm{Li}$, with one spectrometer window centred on $670 \mathrm{~nm}(\mathrm{Li}$ most intense line was considered: $670.78 \mathrm{~nm}$; Table 1; Fig. 3A). However, none of the other elements could be analysed in this spectral range. Therefore, the second spectrometer was centred on $388 \mathrm{~nm}$, as the best compromise to allow analysis of two intense peaks for $\mathrm{Al}$ but only low intensity peaks for $\mathrm{Si}, \mathrm{Fe}$ and $\mathrm{Mg}$ (Table 1; Fig. 3B). The detection limits for $\mathrm{Si}, \mathrm{Fe}$ and $\mathrm{Mg}$ are therefore 3 orders of magnitude higher (Table 1) and their analysis may be qualitative only. Peaks used for calibration of $\mathrm{Li}$ and $\mathrm{Al}$ are both intense resonance lines that could experience self-absorption effects for high-concentration elements. However, Fabre et al. (2002), who calibrated the emission line at $670.78 \mathrm{~nm}$ for Li by the use of synthetic glasses and natural minerals, showed that self-absorption is negligible below 3,000 ppm of Li. Self-absorption may therefore be negligible in the Vanoise bauxite analyses for lithium $(\mathrm{Li}<1750 \mathrm{ppm}$ in host-rocks), but may affect $\mathrm{Al}\left(40-50 \mathrm{wt} \% \mathrm{Al}_{2} \mathrm{O}_{3}\right)$. Menut et al. (2003) measured a single-shot repeatability of $2 \%$ for 100 shots for this LIBS apparatus, and reproducibility of $7 \%$ on the same samples after one year (see Appendix A for details).

For our bauxite analysis, the beam diameter was adjusted to $10 \mu \mathrm{m}$ (diaphragm aperture of $400 \mu \mathrm{m}$, incident laser energy of $120 \mu \mathrm{J})$, as the best compromise between sufficient emission intensity (for low-concentration $\mathrm{Li}$ and low-intensity peaks selected for $\mathrm{Si}, \mathrm{Fe}, \mathrm{Mg}$ ) and good spatial resolution. The resulting crater depth was measured to be 1-1.5 $\mu \mathrm{m}$. Two kinds of LIBS analysis were performed:

- linear profiles of $10 \mu \mathrm{m}$ spots every $10 \mu \mathrm{m}$ (i.e., juxtaposed laser shots; 3,000 analyses points, $3 \mathrm{~cm}$ long profiles; laser shot frequency $10 \mathrm{~Hz}$ ) across cookeite microveins; 
- profiles of $1 \mathrm{~mm}^{2}$ chemical maps, composed of 2,500 individual laser shots (50 x 50) of $10 \mu \mathrm{m}$ diameter, every $10 \mu \mathrm{m}$ in both directions (laser shot frequency $20 \mathrm{~Hz}$; Fig. 3C); the map size was chosen in order to locally average the chemical composition of the rock, i.e., to be larger than the mineral maximal grain size ( $400 \mu \mathrm{m}$ for chloritoid crystals); profiles of 1 $\mathrm{mm}^{2}$ chemical maps, spaced by $1 \mathrm{~mm}$ (Figs. 4-5), were performed between two successive cookeite veins, perpendicular to these veins (profiles of $15 \mathrm{~cm}$ maximal length).

\subsubsection{Data treatment}

For each analysis, peak intensities (Ip = integral of area under the peak) were corrected from background intensities (Ib) and further normalized (i.e., (Ip-Ib)/Ib) to overcome laser energy variations (i.e., shot-to-shot fluctuations), which is the main source of uncertainty for LIBS analysis. This correction is essential for low intensity peaks (i.e., $\mathrm{Si}$ and $\mathrm{Mg}$ ) for which the signal/background ratio can be as low as 2, and allows direct comparison between different element intensities (even if measured on two different spectrometers) and different analyses.

The 2,500 points chemical maps illustrate mainly the distribution of the large chloritoid crystals in the rock (Fig. 3C). To overcome mineral distribution effects and illustrate cookeite distribution in host-rocks between cookeite veins, the average intensity (post treatment) of each element was calculated from the 2,500 shot analysis. In other words, data presented in Figs. 4-5 are profiles of $1 \mathrm{~mm}^{2}$ "spot analysis", expressed in arbitrary units (a.u.). Quantification of LIBS data was not possible here, due to strong matrix effects (see Appendix A for details). However, the intensities of the LIBS analyses being similar over each profiles (Figs. 4-5), we used the chemical analyses of each host-rock to quantify precisely the Li content of the Vanoise samples. 


\section{Results}

\subsection{Samples chosen for analysis}

Thin sections of three samples from the external Alps bauxites, representative of the sedimentary structure variety, were analysed by LIBS: DR7803 (Fig. 4A) which contains numerous rounded pisoids, DR7807 (Fig. 4B), and DR95A5 (Fig. 4C), which is crosscut by diaspore + Al-berthierine veins (see Verlaguet et al., 2011 for chemical analysis and description of these samples).

Four samples of Vanoise metabauxites exhibiting several cookeite veins were selected for LIBS analysis. In the field, bauxites frequently fracture along cookeite veins; therefore it was sometimes difficult to sample the whole vein width. Sample Rat7V4 (Fig. 5A-B) exhibits cookeite en-echelon veins (1 mm wide), and cookeite (+/- pyrophyllite) wider veins are present at both extremities of the sample, two successive veins being separated by about 3-7 $\mathrm{cm}$ of host-rock. This sample is quite rich in both pisoids (concentrating Al-rich minerals, among which cookeite) and cookeite pods and microveins. Similarly, sample Rat7V1 is limited by two cookeite (+ pyrophyllite) veins ( $1 \mathrm{~cm}$ wide) separated by about $4-5 \mathrm{~cm}$ of hostrock (Fig. 5E-F). Sample RatA1 exhibits cookeite en-echelon veins at one end (1 mm wide), and a cookeite $(0.2 \mathrm{~mm}+$ chlorite in its centre $)$ vein at the other extremity, separated by $4 \mathrm{~cm}$ of host-rock (Fig. 5G). Sample RatA2 is also limited by two cookeite veins, although one broke during sampling, and a third very thin cookeite vein, which looks like connected former en-echelon veins, crosscuts the host-rock at a high angle from the two other veins (Fig. 5H). Multiple micrometric cookeite veins crosscut this sample.

\subsection{Chemical composition of host-rocks}

Chemical analyses were performed on 11 host-rocks from samples bearing multiple, almost regularly spaced cookeite veins. These host-rocks exhibit quite scattered $\mathrm{Li}_{2} \mathrm{O}$ contents 
of 0.12-0.39 wt \%, with a mean value of $0.19 \mathrm{wt} \%$ (Table 2). However, 9 of the samples have close $\mathrm{Li}_{2} \mathrm{O}$ concentrations $\left(0.12-0.19 \mathrm{wt} \%\right.$, mean $\left.\mathrm{Li}_{2} \mathrm{O}=0.16 \mathrm{wt} \%\right)$. Only samples RatA2 and RatE2 bear higher $\mathrm{Li}_{2} \mathrm{O}$ contents ( 0.39 and $0.27 \mathrm{wt} \%$, respectively), which can be correlated to abundant pisoids, in which Al-rich minerals, among which cookeite, are generally concentrated. Moreover, RatA2 contains multiple micrometric cookeite veins that were impossible to remove from the host-rock material. More generally, host-rocks showing the highest $\mathrm{Li}_{2} \mathrm{O}$ contents are those presenting pisoid concentrations and/or numerous micrometric cookeite veins (Table 2). Therefore, most host-rocks of samples containing cookeite veins present $\mathrm{Li}_{2} \mathrm{O}$ concentrations of $\sim 0.16 \mathrm{wt} \%$, which is close to the mean $\mathrm{Li}_{2} \mathrm{O}$ content (0.18 wt\%, Verlaguet et al., 2011) of western Vanoise metabauxite samples (bulk rock analyses, i.e., veins + host-rocks and samples devoid of cookeite veins).

Samples devoid of cookeite veins were also analysed: their $\mathrm{Li}_{2} \mathrm{O}$ content is clearly lower (0.07-0.15 wt $\% \mathrm{Li}_{2} \mathrm{O}$, mean $\mathrm{Li}_{2} \mathrm{O}=0.10 \mathrm{wt} \%$; Table 2) compared to that of metabauxite samples exhibiting cookeite veins, presented above.

\subsection{LIBS compositional profiles}

\subsubsection{External Alps bauxites}

LIBS profiles (Fig. 4A-B-C) show that lithium distribution in the three samples analysed is quite homogeneous and gives similar intensity (30-40 a.u.). Li distribution is slightly more variable in DR7803 (Fig. 4A), probably due to the presence of multiple pisoids, which tend to concentrate clay minerals (among which Li-rich smectites). However, these rocks do not show any particular Li enrichment or depletion at the thin section scale. Interestingly, other elements, in particular $\mathrm{Al}$ and $\mathrm{Fe}$, show higher fluctuations than $\mathrm{Li}$.

\subsubsection{Western Vanoise metabauxites}


The spectroscopic lithium profiles for all samples (Fig. 5) are almost flat in the host-rocks, whereas cookeite veins are marked by a straight rise in Li concentration (up to 70-80 a.u.). Indeed, host-rocks do not show any particular Li enrichment or depletion, whatever the vein proximity. Moreover, Li intensity is similar for all samples (5-20 a.u.; Fig. 5) except for RatA2, which seems to be more concentrated in lithium (10-35 a.u.; Fig. 5H). As can be seen on samples Rat7V4 and RatA2, the small en-echelon central veins being locally thinner than the $1 \mathrm{~mm}^{2}$ LIBS maps, they are characterised by only a slight Li increase or no particular Li enrichment respectively (Figs. 4B, H).

Therefore, lithium distribution in the host-rock close to these en-echelon thin veins was studied for sample Rat7V4 with linear profiles of juxtaposed $10 \mu \mathrm{m}$ point analyses. All five profiles give similar results (Fig. 5C): Li profiles in the host-rock are quite flat (10-20 a.u.), and the cookeite vein border is marked by a straight Li increase up to 70 a.u., similarly to thicker cookeite veins. Zones devoid of lithium are scarce, and their maximum size is about 100-250 $\mu \mathrm{m}$ (Fig. 5D), corresponding to the size of chloritoid crystals.

Therefore, the lithium is homogeneously distributed in the host-rocks between two cookeite veins and cookeite vein walls are characterized by step-like lithium increase, whatever the scale of analysis $\left(1 \mathrm{~mm}^{2}\right.$ versus $10 \mu \mathrm{m}$ spots $)$.

Similarly, the concentration of $\mathrm{Al}, \mathrm{Si}$ and $\mathrm{Mg}$ is quite homogeneous in the host-rocks (Fig. 5). In most samples, Fe concentration exhibits larger variations, which may be linked to the large size of the main Fe mineral hosts, chloritoid (up to $\sim 400 \mu \mathrm{m}$ ), compared to the LIBS map size $\left(1 \mathrm{~mm}^{2}\right)$, whereas all other minerals are smaller (i.e., diaspore $\sim 20 \mu \mathrm{m}$, pyrophyllite and cookeite $\sim 1 \mu \mathrm{m})$.

\section{Modelling and interpretation of Li transfer from host-rocks to veins}


Both structural and chemical arguments support the hypothesis that the western Vanoise metabauxites remained chemically isolated during most of their metamorphic cycle (Verlaguet et al., 2011). The similar lithium concentration in both western Vanoise metabauxites and external Alps bauxites, which can be considered in first approximation as the Vanoise bauxite protolith, confirms that Li was already present before metamorphism (Poinssot et al., 1997; Table 2). Moreover, LIBS profiles on external Alps samples (Fig. 4) suggest that Li was homogeneously distributed among the protolith. Therefore, cookeite veins are the result of an internal redistribution of lithium during metamorphism, through the locally-derived fluid phase.

In closed-system conditions, mass transfer from deforming host-rock to veins can take place in the course of a metamorphic reaction (e.g., Cesare, 1994; Widmer and Thompson, 2001). Such a reaction-driven vein filling was observed in the western Vanoise metabauxites, where chloritoid and chlorite vein filling was associated to a prograde and retrograde reaction, respectively (Fig. 1B; Verlaguet et al., 2011). On the contrary, Verlaguet et al. (2011) showed that the vein cookeite cannot be the result of the cookeite-in reaction or any other metamorphic reaction. Therefore, cookeite first formed in the host-rock and was later transferred from host-rock to opening veins. In these high-pressure rocks closed to external fluid infiltration (Verlaguet et al., 2011), fluid advection may have been very limited by the restricted permeability. Cookeite-forming elements were thus most likely transferred from host-rock to veins by diffusion through the intergranular fluid medium, since mineral volume diffusion can be neglected at these low-temperature conditions.

\subsection{Characteristic distance of diffusive mass transfer}

LIBS flat profiles for Li between two successive cookeite veins suggest that cookeite is now homogeneously distributed in the host-rock. Therefore, although the aqueous fluid may 
have been mostly localised in veins, cookeite diffusive transfer towards veins suggests that the vein fluid was somehow connected to the intergranular fluid network and interacted with the entire host-rock volume which separates two cookeite veins, i.e., the fluid-rock interaction distance is about a few $\mathrm{cm}(2-4 \mathrm{~cm})$. Therefore, diffusive mass transfer was effective on a minimum distance of 2-4 cm, at least for $\mathrm{Li}$. Indeed, $\mathrm{Al}$ and $\mathrm{Si}$ were not necessarily transferred on the entire distance. Cookeite selective transfer to veins required a higher solubility of cookeite in the host-rock fluid than in the vein fluid, while the solubility of other minerals remained constant. The activity diagram (Fig. 6) shows that Si concentration in the fluid is locally buffered by pyrophyllite solubility, and Al concentration is similarly buffered by diaspore solubility. An increase in cookeite solubility only will thus result in cookeite incongruent dissolution (i.e., diaspore and pyrophyllite precipitation to maintain $\mathrm{Al}$ and $\mathrm{Si}$ equilibrium concentrations in the fluid) and increase in aqueous $\mathrm{Li}$ only. Thus selective cookeite solubility increase in the host-rock should result in lithium chemical potential gradients between host-rock and veins, and thus only Li should diffuse towards the veins. When Li reaches the vein, cookeite crystallization (i.e., lower cookeite saturation state) requires dissolution of both diaspore and pyrophyllite in the vein vicinity. However, calculations show that diaspore dissolution in a restricted rock volume of $1 \mathrm{~cm}$ around veins would result in a minimum depletion of $15-25 \mathrm{wt} \%$ of $\mathrm{Al}$. Such $\mathrm{Al}$ depletion around veins is not visible on the LIBS profiles (Fig. 5), suggesting that diaspore and pyrophyllite dissolution was more likely spread over a larger host-rock volume around veins. Therefore, the diffusion distance for $\mathrm{Al}$ and $\mathrm{Si}$ may be smaller than for $\mathrm{Li}$, but may at least reach $2-3 \mathrm{~cm}$. A smaller diffusion distance for $\mathrm{Al}$ and $\mathrm{Si}$ would be consistent with their slower diffusivity in aqueous fluid compared to Li that could reach one order of magnitude (charge-dependant diffusion coefficients; Carlson, 2010; Carmichael, 1969; Oelkers and Helgeson, 1988; Watson and Wark, 1997). 


\subsection{Amount of Li transferred to veins and residual cookeite in host-rocks}

Li was obviously highly transferred to veins, but not completely depleted from hostrocks, and residual cookeite remained homogeneously distributed in each studied sample (flat Li profiles, Fig. 5). Calculations show that $43-63$ vol\% of cookeite was transferred to veins for the analysed samples (except for RatA2, 28 vol\%; Table 3), which host-rocks had initially close bulk-rock $\mathrm{Li}$ contents $\left(0.26-0.36 \mathrm{wt} \% \mathrm{Li}_{2} \mathrm{O}\right.$; Table 3). The 2 samples showing the highest residual cookeite amounts in host-rocks were proportionally initially richer in cookeite (i.e., RatA2 and RatE2; see Table 3 for details on the calculations) and are characterized by numerous cookeite microveins. It is interesting to note that these 9 samples, which developed multiple cookeite veins, were all initially particularly Li-rich among the variety of Vanoise bauxites $\left(0.07-0.36 \mathrm{wt} \% \mathrm{Li}_{2} \mathrm{O}\right.$ for bulk rocks; Verlaguet et al., 2011). Although cookeite transfer to veins was efficient enough to drive about half of the sample cookeite towards veins, their host-rocks remained richer in cookeite $\left(0.12-0.39\right.$ wt\% $\left.\mathrm{Li}_{2} \mathrm{O}\right)$ than most rocks that did not develop any cookeite vein (0.07-0.15 wt $\% \mathrm{Li}_{2} \mathrm{O}$; Table 2).

Residual cookeite in host-rocks is partly composed of anhedral individual micrometric fibres dispersed in the host-rock, and of euhedral sheets crystallized in microveins and 30-100 $\mu \mathrm{m}$ pods (Fig. 2G-H), which may be as stable as bigger vein cookeite (i.e., similar solubility in aqueous fluid). The proportion of each is difficult to determine (as $\mathrm{Li}$ cannot be analysed by SEM or microprobe) and varies among samples.

\subsection{Cookeite transfer to veins: achieved or frozen?}

LIBS flat and non-zero Li compositional profiles (Fig. 5) between two veins can be interpreted in two ways: (1) either mass transfer from host-rock to vein at the cm-scale was interrupted (frozen non-zero profile) while following a regime where elemental diffusion was 
not the limiting factor (flat profile), (2) or chemical diffusion proceeded until the chemical potential that drove diffusion vanished, leaving in the host-rock homogeneously distributed cookeite in chemical equilibrium with vein cookeite (i.e., with a solubility in the fluid identical to that of the vein cookeite; Figs. 7, 8). Indeed, mass transfer to veins required cookeite dissolution in the host-rock, elemental diffusion towards veins, and cookeite crystallization in veins, the slowest of these three processes being the limiting factor. In case 1, mass transfer to veins would have been limited by cookeite dissolution rate in the host-rock or crystallization in veins, rather than diffusion, to generate flat Li profiles (Fig. 7A). In case 2, mass transfer was rather diffusion-limited, which generated transient Li bell-shape diffusion profiles in the host-rock that were finally erased by complete mass transfer (Figs. 7B, 8). In this latter case, only half of the initial host-rock cookeite was obviously concerned by transfer to veins (i.e., "unstable" cookeite).

\subsubsection{Modelling Li transfer from host-rocks to veins}

Euhedral crystallization in veins of cookeite (although not associated to any fluid release) but also of geodic retrograde chlorite (i.e., hydration reaction) clearly shows that part of the metamorphic fluid liberated along the prograde path ( 13 vol\%, Verlaguet et al., 2011) remained in the metabauxite lenses during peak P-T conditions and along most of the retrograde path, the surrounding less permeable carbonates most likely preventing fluid escape. Therefore, a free fluid phase was potentially present in the Vanoise bauxites, at least locally and transiently. To estimate the range of relative cookeite kinetic constants $(\mathrm{k})$ versus Li diffusion coefficient (D) in each case, we modelled Li diffusion from host-rock to veins over $4 \mathrm{~cm}$ in a free fluid phase, with a reaction-diffusion Matlab code based on a 1D finite element method (Crank, 1975; see Appendix B for details). Cookeite transfer to veins required a local difference in cookeite solubility in the fluid phase between the host-rock 
pores (cookeite undersaturation driving its dissolution) and the veins (cookeite supersaturation driving its crystallization). In the model, Li concentration in the host-rock fluid was first taken as twice that in the vein fluid $\left(\mathrm{C}_{\mathrm{Li}}{ }^{\mathrm{HR}}=2 \mathrm{C}_{\mathrm{Li}}{ }^{\mathrm{V}}\right)$, and porosity was taken as $1 \%$. Cookeite transfer to veins was modelled over $1 \mathrm{Ma}$, which represents the maximum duration for cookeite vein formation (between point 3 and 4, Fig. 1B) as the duration of the metamorphic peak in the Vanoise bauxites was estimated to $1.7 \mathrm{Ma}$ (Monié, 1990). Note that this simplistic, purely diffusive, model aims at giving tendencies and does not pretend to derive absolute $\mathrm{k}$ and $\mathrm{D}$ values.

The model suggests that to reach $50 \mathrm{~mol} \%$ of Li transfer to veins (mean host-rock depletion, Table 3) with final flat Li profiles (case 1, reaction-limited) requires $\mathrm{D} \geq 10^{-12}-10^{-13} \mathrm{~m}^{2} \cdot \mathrm{s}^{-1}$ for $\mathrm{k} \leq 10^{-7} \mathrm{~g} \cdot \mathrm{cm}^{-2} \cdot \mathrm{y}^{-1}$. In case 2 (diffusion-limited), complete transfer of the "unstable cookeite", corresponding to Li diffusion profiles flattened after $1 \mathrm{Ma}$, may be achieved for a minimum D of $10^{-13} \mathrm{~m}^{2} \cdot \mathrm{s}^{-1}$ and associated $\mathrm{k} \geq 10^{-6} \mathrm{~g} \cdot \mathrm{cm}^{-2} \cdot \mathrm{y}^{-1}$ (Table B1). Higher D would extend the range of $\mathrm{k}$ to lower values.

\subsubsection{Effect of porosity and chemical potential gradient variations}

Porosity decrease from $1 \%$ to $0.1 \%$ has a similar effect as decreasing D by 1 order of magnitude, i.e., the observed cookeite mass transfer to veins in a $0.1 \%$ porosity rock would require $\mathrm{D} \geq 10^{-12} \mathrm{~m}^{2} \cdot \mathrm{s}^{-1}$. Variations in Li chemical potential gradients imply greater variations on Li transfer: considering $\mathrm{C}_{\mathrm{Li}}{ }^{\mathrm{HR}} / \mathrm{C}_{\mathrm{Li}}{ }^{\mathrm{V}}=1.25$ and 1.01 (instead of 2) is barely equivalent to a D decrease by 1 and 3 orders of magnitude, respectively. This means that if Li transfer to veins was driven by a small cookeite supersaturation state in the host-rock fluid (1.01), the observed cookeite transfer to veins required a minimum $\mathrm{D}$ of $10^{-10} \mathrm{~m}^{2} . \mathrm{s}^{-1}$ to be achieved in 1 Ma (Appendix B; Table B1). The supersaturation state of cookeite in the host-rock fluid 
compared to veins is unknown and will be discussed later in light of the potential driving forces for Li transfer.

\subsubsection{Significance of $D$ and $k$ values}

$\mathrm{Li}^{+}$bulk diffusivity $\left(\mathrm{D}_{\text {bulk }}^{\mathrm{Li}}\right)$ in a free fluid phase at $360^{\circ} \mathrm{C}$ (i.e., peak temperature for the Vanoise metabauxites) was calculated to be about $10^{-8} \mathrm{~m}^{2} \cdot \mathrm{s}^{-1}$ (Oelkers and Helgeson, 1988). To take into account the geometry of the diffusive pathway in natural rocks, and considering literature values for tortuosity $(\tau=0.3-0.8$; Bear, 1988; Emmanuel and Berkowitz, 2007; Watson and Wark, 1997), $\mathrm{Li}^{+}$diffusivity may be about $5 \cdot 10^{-9} \mathrm{~m}^{2} \cdot \mathrm{s}^{-1}$. However in fluid-bearing rocks, in the absence of an interconnected free fluid-filled porosity, elements may diffuse along grain boundary fluid films, with drastically lower diffusion coefficients (Carlson, 2010; Farver and Yund, 2000; Gardès et al., 2012). There is no data about Li grain boundary diffusion coefficients, but Kelly et al. (2013) calculated Al diffusion coefficients in fluidsaturated grain boundaries $\left(\mathrm{D}_{\mathrm{GB}}\right)$ of $\sim 10^{-14}-10^{-15} \mathrm{~m}^{2} \cdot \mathrm{s}^{-1}$ at $360{ }^{\circ} \mathrm{C}$ from metapelites. Diffusion coefficients being charge dependant, $\mathrm{D}_{\mathrm{GB}}{ }^{\mathrm{Li}}$ could be about 1 order of magnitude higher than $\mathrm{D}_{\mathrm{GB}}{ }^{\mathrm{Al}}$ (Carlson, 2010; van Noort et al., 2011).

The above 1D model shows that the observed cookeite transfer to veins requires $\mathrm{Li}$ diffusion coefficients of about $10^{-13}-10^{-10} \mathrm{~m}^{2} \cdot \mathrm{s}^{-1}$ (depending on porosity and supersaturation values), thus ranging between saturated grain boundary diffusivity and Li diffusivity in a free fluid phase. Such rapid diffusion rates are rather unusual for low-temperature $\left(360{ }^{\circ} \mathrm{C}\right.$, Fig. 1$)$ and relatively high-pressure (i.e., restricted porosity) rocks, in which grain boundary diffusion is rather observed (Carlson, 2010; Kelly et al., 2013), but are coherent with the attested preservation of a fluid phase in the Vanoise bauxites at peak conditions and after. Therefore, Li may have been transferred, at least partly, through a connected free fluid phase present in the intergranular medium, with some contribution of grain boundary Li diffusion. 
The kinetic constant $\mathrm{k}$ includes both dissolution and crystallization rates. Preferential crystallization of minerals is often observed in fluid-filled open veins, which seem to offer energetically favourable nucleation and growth sites (e.g., chloritoid and chlorite veins in these Vanoise bauxites, Verlaguet et al., 2011). Thus k rather represents the rate of Li release (or flux) into the fluid-filled diffusive network, i.e., the dissolution rate of host-rock cookeite plus Li transport to the connected fluid-filled porosity. In case 2 (diffusion-limited, $100 \%$ of Li transfer), the slowest $\mathrm{D}^{\mathrm{Li}}\left(10^{-13} \mathrm{~m}^{2} . \mathrm{s}^{-1}\right)$ would require kinetic rates of about $10^{-5}-10^{-6} \mathrm{~g} . \mathrm{cm}^{-}$ ${ }^{2} \cdot \mathrm{y}^{-1}$, which is clearly higher than regional metamorphism reaction rates $\left(10^{-8}-10^{-9} \mathrm{~g} \cdot \mathrm{cm}^{-2} \cdot \mathrm{y}^{-1}\right.$; Baxter, 2003) but remains lower than laboratory-determined reaction rates in free fluids $\left(10^{-4}\right.$ $10^{-2}$ g. $\left.\mathrm{cm}^{-2} \cdot \mathrm{y}^{-1}\right)$. Higher D values would be associated to a large range of potential reaction rates. Such a set of D (intermediate between diffusion in free fluid and in saturated grain boundaries) and intermediate reaction rates is in agreement with the obvious presence of a free fluid phase in the Vanoise bauxites, somewhat transient and spatially limited. In contrast, most regional metamorphic rocks are characterized by a limited fluid availability and slow element diffusive transfer in the intergranular medium at peak conditions (e.g., Baxter and DePaolo, 2002; Rubie, 1986), as the fluid produced by prograde dehydration reactions rather escapes upward, and retrograde fluid infiltration may be localized in fractures or high strain zones (e.g., Boutoux et al., 2014a; Marquer and Burkhard, 1992; Rolland et al., 2003).

In contrast, flat Li profiles (case 1, reaction-limited; Fig. 7A) may have developed in hostrocks for kinetic constants $\leq 10^{-7} \mathrm{~g} \cdot \mathrm{cm}^{-2} \cdot \mathrm{y}^{-1}$, which is close to the slow reaction rates measured in regional metamorphic rocks. Yet the high diffusion coefficients modelled in this study clearly stress for efficient fluid-filled diffusion pathways. Therefore in this case, although lithium diffusion may have been efficiently achieved through rapid diffusion pathways, the overall Li transfer may have been limited by a relatively slow Li release in the diffusive network, suggesting the existence in the host-rock of micro-domains with limited fluid 
availability and consequently slow cookeite dissolution and, most likely, diffusion towards the diffusive network (Fig. 8). Such fluid-isolated domains may be small (i.e., invisible by $\mathrm{mm}^{2}$-scale LIBS analyses; Fig. 5) and diffusive networks variable in space and time (not recorded in host-rocks).

\section{Discussion}

Vein formation is a twofold mechanism: mechanical opening and chemical transfer (followed by crystallization), which may be directly linked or not. Here we will discuss the potential driving forces for each of these mechanisms successively.

\subsection{Cookeite vein opening processes}

Cookeite growth in veins occurred in two successive steps, characterized by different growth conditions: the first generation of fibrous cookeite (symmetrical on both vein sides; Fig. 2) suggests that crystallization occurred in a restricted dilating space (Bons et al., 2012; Oliver and Bons, 2001), cookeite growth being limited by the vein opening rate as shown by the occurrence of oblique cookeite fibres that recorded the shearing displacement of the vein walls (Verlaguet et al., 2011). Vein conditions then changed, and cookeite fan-shaped euhedral sheets (syntaxial growth; Fig. 2) obviously formed in a fluid-filled open space (Fisher and Brantley, 1992; Oliver and Bons, 2001). However, numerous micrometric cookeite fibrous veins (width $<20 \mu \mathrm{m}$; Figs. 2G; 8) can be observed in several samples, suggesting that many veins aborted and only few evolved towards thicker fluid-filled veins. The following observations support the hypothesis that euhedral cookeite veins could be former en-echelon fibrous veins that connected and coalesced, giving rise to fluid-filled openspaces (Fig. 8; Verlaguet et al., 2011): (1) en-echelon veins tend to connect to each other when they reach 2-3 cm long and (Fig. 2D), (2) wider cookeite veins often exhibit irregular walls with multiple fibrous terminations (Figs. 2B, C). Quite similar coalescent en-echelon 
vein structures giving rise to sigmoid host-rock inclusions (Figs. 2A; 8) are reported by Bons et al. (2012).

A question arises concerning the opening mechanism of the first fibrous veins: did cracks form as a result of differential stress or pressure of crystallization (Fletcher and Merino, 2001; Hilgers and Urai, 2005; Means and Li, 2001; Taber, 1916; Wiltschko and Morse, 2001)? Even if this mechanism cannot be completely ruled out, it seems unrealistic here that cracks could have been forced by growing cookeite crystallization pressure, as this mineral formed tiny anhedral sheets dispersed in the host-rock rather than euhedral porphyroblastic crystals, contrary to other minerals such as chloritoid or diaspore. Moreover, most arguments suggest a mechanically-enhanced cracking mechanism: cookeite veins present a rather parallel orientation and quite regular distribution, and clearly cut across chloritoid porphyroblasts (Fig. 2G; 8). Their regular shape would discard a hydrofracturing process, which is coherent with the absence of any coeval fluid-release reaction (Verlaguet et al., 2011). The en-echelon arrangement of veins associated to oblique fibre growth and linkage of en-echelon arrays rather suggest that the veins opened by extensional shear (i.e., hybrid fractures; Cesare, 1994; Etheridge, 1983; Ramsey and Chester, 2004). Such extensional shear failure requires lower fluid pressures and higher confining pressures than tensile failure (Ramsey and Chester, 2004), which fits well with the pressure increase at peak conditions under which cookeite veins formed (Fig. 1B). Extensional shear failure also requires low to moderate differential stresses ( 10-50 MPa, Etheridge, 1983), which is supported by the cookeite en-echelon arrays, scarce shear bands and moderate elongation of some pisoids perpendicular to cookeite veins (Fig. 2). Note that on the contrary, the differential stress may have been very low during the prograde path, as suggested by the radiating structures in all directions of chloritoid crystals and their absence of further deformation, and the overall weak deformation of these metabauxite lenses (see Verlaguet et al., 2011 for details). Such low differential stresses, 
commonly inferred during burial of HP-LT rocks in subduction zones (Shimizu, 1995; Wassmann and Stöckhert, 2013), associated to high fluid pressures generated by prograde reactions, are coherent with the hydrofracturing and tensile crack formation observed for prograde chloritoid veins.

Interestingly, cookeite microveins sometimes nucleated on tiny cookeite clusters (30-100 $\mu \mathrm{m})$ : the incipient shearing movement was obviously localized on the cookeite sheets dispersed in the host-rock, which then served as seeds for on-going cookeite crystallization in dilating spaces. Indeed, the presence of phyllosilicates in rocks is supposed to enhance and localize shear deformation (i.e., softening behaviour, Moore and Rymer, 2007; Niemeijer et al., 2010). However, another phyllosilicate, pyrophyllite, was much more abundant in these rocks (15-30 vol\%), so the cookeite preferential transfer to veins needs to be clarified. Indeed, pyrophyllite was also extensively transferred from host-rock to parallel veins, but only after cookeite transfer was achieved (pyrophyllite veins postdate cookeite ones, Fig. 1). Interestingly, in Li-poor metabauxites, thus devoid of cookeite veins, the shear movement localised on micrometric veins of fibrous pyrophyllite (Fig. 2I).

\subsection{Potential driving forces for selective mass transfer to veins}

Although phyllosilicates generally remain in the host-rock (i.e., residue) in classical metapelites, in Vanoise metabauxites it is the phyllosilicates that were preferentially transferred to veins. In the following, we will explore the potential driving forces for selective cookeite (followed by pyrophyllite) transfer towards veins, in these Al-rich rocks, devoid of quartz and carbonate, in light of the Li transfer modelled above.

The diffusive transfer of cookeite-forming elements towards veins required the development of chemical potential gradients between host-rocks and veins. As exposed above, Vanoise metabauxites remained closed to external fluid infiltration, which precludes 
any infiltration-driven reaction (e.g., Austrheim et al., 1987; see John et al., 2012 and Penniston-Dorland et al., 2010, for Li diffusion profiles). Moreover, Li transfer to veins was not associated to any metamorphic reaction, i.e., cookeite was already the stable Li-host (Verlaguet et al., 2011). Therefore, cookeite crystallization in veins may result from either a decrease in cookeite solubility in the rock fluid (due to P-T variations, Goffé et al., 1987; Verlaguet et al., 2006), associated to preferential cookeite crystallization in veins, or a spatial difference in cookeite solubility in the fluid phase between the host-rock pores and the veins. Such a solubility gradient may result from a difference in (e.g., Gratier and Guiguet, 1986; Putnis, 2002): (1) normal stresses, driving pressure-solution in the rock (Renard et al., 1997), (2) surface or interfacial energy (Nakamura and Watson, 2001; Putnis and Mauthe, 2001), (3) elastic or plastic strain energy (Dewers and Ortoleva, 1990; Stunitz, 1998; Wintsch and Dunning, 1985), (4) surface electrochemical potentials (Greene et al., 2009; Kristiansen et al., 2011). In the presence of a fluid phase, small differences in free energy may be sufficient to drive dissolution-precipitation processes (Putnis, 2002).

The contribution of strain energy to mineral internal energy enhancement (and subsequent solubility increase) may be important only in mylonites or shear zones (Dewers and Hajash, 1995; Tada et al., 1987; Wintsch and Dunning, 1985). Therefore, strain solution is unlikely to explain phyllosilicate transfer to veins in these almost undeformed Vanoise bauxites. Experimental data suggest that quartz dissolution rate at the contact of mica increases proportionally to the electrical potential gradient developed by $\mathrm{K}^{+}$release from the mica surface (Greene et al., 2009; Kristiansen et al., 2011; Meyer et al., 2006). In the Vanoise metabauxites, similar $\mathrm{Li}^{+}$release from cookeite surface should therefore enhance diaspore and pyrophyllite dissolution, which is clearly not the case. In the absence of data on the relative electrical potential of these minerals, the validity of this mechanism to explain cookeite transfer to veins cannot be properly evaluated. Therefore, among the potential driving forces 
for cookeite and pyrophyllite mass transfer to veins, only the role of P-T variations, stress and mineral-fluid interfacial energy will be considered.

\subsubsection{Mineral precipitation as a result of $P-T$ variations}

Aside from reactions, slight variations in mineral solubility may arise continuously from both $\mathrm{P}$ and $\mathrm{T}$ variations along the prograde and retrograde path: small amounts of minerals are supposed to dissolve or crystallize to maintain fluid-mineral equilibrium along P-T variations (Goffé et al., 1987; Goffé and Vidal, 1992; Verlaguet et al., 2006). Such minerals could preferentially crystallize into fluid-filled open veins, which seem to offer energetically favourable nucleation and growth sites (e.g., Cesare, 1994; Widmer and Thompson, 2001; Verlaguet et al., 2006). Cookeite solubility decreases and increases with increasing $\mathrm{T}$ and $\mathrm{P}$, respectively, and calculations suggest that cookeite solubility may not vary much around the peak P-T conditions (points 3 to 4, Fig. 1; see Appendix C for more details). Interestingly, pyrophyllite solubility increases with both $\mathrm{P}$ and $\mathrm{T}$, suggesting that pyrophyllite will tend to crystallize along the retrograde path, as was observed experimentally by Goffé et al. (1987). Calculations of Vanoise mineral solubility in pure $\mathrm{H}_{2} \mathrm{O}$ fluid show that the amount of crystallized pyrophyllite during the retrograde path (Fig. 1) is fairly small and cannot account, alone, for the whole amount of pyrophyllite displaced to veins. However, the fluid composition may be more complex in natural metabauxites: the potential presence of $\mathrm{NaCl}$ or other ligands, and potential formation of alkali-bearing complexes with Li (e.g., Newton and Manning, 2003; Pokrovskii and Helgeson, 1997) may increase mineral solubilities (Alcantar et al., 2003; Gratier and Guiguet, 1986; Kowacz and Putnis, 2008), but essentially at high temperature conditions. So the contribution of pyrophyllite crystallization into veins as a result of $\mathrm{P}$ and $\mathrm{T}$ decrease along the retrograde path may be small, but however not completely negligible (e.g., Beitter et al., 2008). 


\subsubsection{Stress-induced mass transfer: the pressure-solution mechanism}

Dissolution-precipitation creep is considered to occur in response to differential stresses that induce mineral solubility differences in the intergranular fluid, between the stressed crystal faces (where dissolution occurs) and dilating sites (i.e., strain shadows, veins) where minerals precipitate (Croizé et al., 2010; Renard et al., 1997; Rutter, 1983; Weyl, 1959). Pressure-solution creep occurs at low differential stress (1-100 MPa) in low temperature rocks $\left(<400^{\circ} \mathrm{C}\right)$, in the presence of a pervasive fluid phase (Gratier and Guiguet, 1986; Rutter, 1976), which is consistent with the Vanoise metabauxite setting. Moreover, although deformation structures are scarce in the Vanoise bauxites, the extensive phyllosilicate (cookeite then pyrophyllite) dissolution and fluid-assisted transfer to almost parallel cracks obviously accommodated part of the rock deformation (Fisher et al., 1995; Yardley and Bottrell, 1992; Wintsch and Yi, 2002). This is in agreement with most recent studies in HPLT metamorphic environments in which dissolution-precipitation creep, associated to mass transfer towards metamorphic veins, is recognized as the main deformation mechanism (see Wassmann and Stöckhert, 2013 for a review).

Pressure-solution creep is therefore a viable mechanism for explaining diffusive mass transfer from the stressed host-rock pores to opening veins in the Vanoise bauxites. However, cookeite (followed by pyrophyllite) growth in veins required fluid supersaturation with respect to cookeite (and then pyrophyllite) specifically. We calculated the impact of a stress difference on the relative mineral solubility in the aqueous fluid $\left(S_{0}\right)$ among the Vanoise bauxite minerals (diaspore + cookeite + pyrophyllite + chloritoid + muscovite + paragonite) at $360^{\circ} \mathrm{C}$ (peak temperature) with the geochemical software Arxim (see Table 4 and Appendix C for details). A pressure increase of $10 \mathrm{MPa}$ implies dissolution of both pyrophyllite and cookeite (+ minor paragonite, muscovite and chloritoid; Table 4), and precipitation of 
diaspore (Fig. 9). Therefore, pyrophyllite and cookeite present the highest solubility variation with pressure, which suggests that these two minerals will be preferentially dissolved along stressed interfaces (higher pressure) in host-rocks and precipitated into veins (lower pressure sites), which is in agreement with the observed vein sequence (cookeite followed by pyrophyllite veins; Fig. 1B). Moreover, their dissolution rate may be favoured by their very small grain size ( $\sim 1 \mu \mathrm{m}$ wide sheets) compared to other minerals (i.e., chloritoid up to 400 $\mu \mathrm{m}$, diaspore $\sim 20 \mu \mathrm{m})$, i.e., higher reactive surface.

However, this simplified calculation suggests that stress-induced pyrophyllite dissolution could be slightly favoured over cookeite transfer (Table 4), although their solubility variation with pressure is of the same order of magnitude. First, note that this result may be taken with caution considering the uncertainty of this rough calculation, made at $0.5 \mathrm{GPa}$ instead of 1.2 GPa for peak pressure (due to the limitation in the aqueous species thermodynamic data). Moreover, as noted above, the fluid composition may be more complex in natural metabauxites, which slightly influences mineral solubilities (e.g., Alcantar et al., 2003). Moreover, Li diffusion coefficient is supposed to be higher than for Al or Si (Carlson, 2010; van Noort et al., 2011). The thickness of the fluid film (w) at the stressed grain contact may also be larger for alkali-bearing phyllosilicates such as cookeite (Alcantar et al., 2003; Renard and Ortoleva, 1997; Renard et al., 1997). This potential faster diffusion of Li along chemical potential gradients may have clearly favoured cookeite (over pyrophyllite) transfer to veins, if mass transfer was diffusion limited (case 2). In this case, shift from cookeite to pyrophyllite transfer to veins occurred after Li potential gradients were erased, i.e., when only cookeite protected from differential stresses remained in the host-rock (Fig. 8). In case of reactionlimited mass transfer (case 1), the shift from cookeite to pyrophyllite transfer to veins could reflect the onset of the retrograde P-T path: the decrease in pyrophyllite solubility with decreasing $\mathrm{P}$ and $\mathrm{T}$ may enhance pyrophyllite supersaturation and subsequent crystallization 
in veins, favouring pyrophyllite (over cookeite) stress-induced transfer to veins. Note that differential stresses may have been about 10-50 MPa (extensional shear veins, Etheridge, 1983), which would imply low cookeite supersaturation states (i.e., $\mathrm{C}_{\mathrm{Li}}{ }^{\mathrm{HR}} / \mathrm{C}_{\mathrm{Li}}{ }^{\mathrm{V}}$ of 1.01-1.15). The observed cookeite mass transfer to veins would therefore have required high Li diffusion coefficients $\left(10^{-10}-10^{-12} \mathrm{~m}^{2} \cdot \mathrm{s}^{-1}\right.$, Table B2).

Such a preferential transfer of phyllosilicates to veins is rather unusual, as in classical metapelites and metamarls, micas tend to remain in the host-rock. Their presence is even observed to enhance quartz and calcite dissolution, in both natural and experimental samples (Alcantar et al., 2003; Nenna and Aydin, 2011; Renard and Ortoleva, 1997). However, the above calculations show that in the Vanoise bauxites, stress-induced mass transfer would result in selective phyllosilicate transfer to veins during metamorphism, as these phases present the highest solubility variations with pressure. For comparison, similar calculations were carried out for classical Liassic quartz-carbonate-bearing metamarls from Oisans (external French Alps), metamorphosed under greenschist facies conditions $\left(350{ }^{\circ} \mathrm{C}, 0.2-0.5\right.$ GPa) during the Alpine orogeny (Boutoux et al., 2014a; 2014b; Gratier and Vialon, 1980). Several generations of quartz-calcite veins formed all along the deformation process, and their filling was interpreted as the result of pressure-solution. A pressure increase of $10 \mathrm{MPa}$ implies the preferential dissolution of quartz, calcite and cookeite (but scarce in these rocks, < 0.3 vol\%) plus minor muscovite and chlorite (Table 4), and the crystallization of pyrophyllite. Muscovite is supposed to be dissolved in response to a pressure increase, but in negligible amount compared to quartz ( $<$ by $2-3$ orders of magnitude, Table 4 ), which may partly explain the frequent observation that micas remain in the host-rock during quartz preferential transfer to veins. Thus the relative mineral solubility variation with pressure seems to be the chief controlling parameter for pressure-solution creep. 


\subsubsection{Mass transfer driven by interfacial energy gradients (Ostwald ripening)}

Chemical potential gradients may also be due to interfacial energy differences between the host-rock pores and veins. Indeed, fluids in finely porous media (i.e., micro- to nanometric pores) are known to maintain much higher supersaturation levels than free fluids in larger pores, which results in preferential crystallization in the largest pores (Emmanuel and Berkovitz, 2007; Emmanuel et al., 2010; Putnis et al., 1995; Putnis and Mauthe, 2001; Putnis, 2002; Rijniers et al., 2005). Moreover, Nakamura and Watson (2001) measured experimentally that a small solubility difference $\left(2.410^{-2}-2.310^{-1} \mathrm{wt} \%\right)$ is sufficient to drive mineral dissolution-precipitation via the fluid phase. Such a pore-size controlled solubility gradient between small pores in the stressed host-rock, maintaining a high supersaturation level, and open fluid-filled veins, where the threshold supersaturation required for mineral nucleation and growth may be lower, could be the driving force for diffusive mass transfer in the Vanoise metabauxites.

The effective mineral solubility $\left(S_{\delta}\right)$ in a pore of diameter $\delta$ can be expressed, in first approximation, as follows (Emmanuel et al., 2010; Putnis and Mauthe, 2001; Scherer, 2004):

$$
S_{\delta}=S_{0 \cdot} \exp \left(\frac{2 \cdot V m \cdot \gamma \cdot \cos \theta}{R \cdot T \cdot \delta}\right)
$$

where $S_{0}$ is the bulk mineral solubility in these P-T conditions, $V m$ the mineral molar volume, $\gamma$ the interfacial energy, $\theta$ the dihedral angle, $R$ the gas constant and $T$ the temperature. Although no data exist for interfacial energy of chloritoid, diaspore or cookeite, comparisons can be made. In the Vanoise bauxites, these minerals exhibit drastically different morphologies in the host-rock: the very small size $(\sim 1 \mu \mathrm{m}$ width $)$ of phyllosilicate sheets, and thus enhanced surface area, may have conferred them a high surface/volume energy (Putnis, 2009; Tada et al., 1987; Wintsch, 1985) compared to that of large euhedral chloritoid (up to $400 \mu \mathrm{m}$ long $)$ or diaspore $(\sim 20 \mu \mathrm{m})$ crystals texturally equilibrated. Moreover, these micrometric sheets may have been confined into proportionally small pores $(\delta)$, sustaining a 
high effective solubility (Fig. 8). Phyllosilicates may thus present the highest solubility difference (i.e., between $S_{\delta}$ in host-rock pores and $S_{0}$ in vein free fluid), which could explain the selective transfer of these anhedral phases only to veins, where they formed euhedral fanshaped crystals. This process is comparable to Ostwald ripening, during which large crystals grow at the expense of smaller more soluble ones (e.g., Putnis, 2009; Steefel and VanCappellen, 1990).

The effective solubility of cookeite may be higher than that of pyrophyllite due to its higher molar volume ( $V m$, eq. 1; Table 4), which may account for its preferential transfer to veins. Potential faster diffusion of $\mathrm{Li}$ (compared to $\mathrm{Si}$ and $\mathrm{Al}$ ) may also have favoured cookeite (over pyrophyllite) transfer to veins, in case of diffusion-limited mass transfer (case 2). In this case, shift from cookeite to pyrophyllite transfer to veins occurred after annihilation of $\mathrm{Li}$ potential gradients, i.e., when only cookeite with an effective solubility close to $S_{0}$ remained in the host-rock (microveins and pods, Fig. 8). In case of reaction-limited mass transfer (case 1), the shift from cookeite to pyrophyllite transfer to veins could, again, reflect the onset of the retrograde P-T path (Fig. 1): pyrophyllite supersaturation (due to decreasing P and T) may have caused euhedral pyrophyllite crystallization in veins, subsequently driving preferential interfacial energy-driven transfer of pyrophyllite.

\section{Conclusions}

During Alpine metamorphism, cookeite (Li-Al-rich chlorite) veins formed at peak P-T conditions $\left(360{ }^{\circ} \mathrm{C}-1.2 \mathrm{GPa}\right)$ in Vanoise metabauxites. Cookeite veins record a two-step opening process: fibrous cookeite grew in restricted opening microveins (sometimes enechelons, extensional shear veins), part of which evolved towards thicker fluid-filled open veins in which euhedral fan-shape cookeite crystals grew syntaxially. Later growth of euhedral pyrophyllite occurred in the median plane of the largest veins. Both minerals were 
selectively transferred from host-rock to veins, through a dissolution-diffusion-precipitation process that occurred without any fluid infiltration (closed-system) or metamorphic fluid release (no coeval reaction). Although cookeite was highly transferred to veins, LIBS Li profiles show that about half of the initial cookeite remains homogeneously distributed (at the $\mathrm{mm}^{2}$-scale of the LIBS maps) in host-rocks.

These flat Li profiles suggest that the vein fluid interacted with the entire host-rock volume that separates two cookeite veins, i.e., the diffusion distance is about 2-4 cm, at least for $\mathrm{Li}$. In these bauxite lenses, which are embedded in relatively impermeable carbonates, the fluid produced by mineral dehydration along the prograde path is likely to be available during most of the metamorphic cycle as indicated by the crystallization of hydrous minerals (e.g., chlorite) on the retrograde path. A simple 1D reaction-diffusion model, which assumes a fluid-filled porosity network, is able to account for these flat profiles assuming Li diffusion coefficients and rates of mineral-water interaction consistent with literature values for waterbearing systems. Flat and non-zero LIBS Li profiles between two veins can be interpreted in 2 ways: (1) mass transfer from host-rock to vein was interrupted (frozen non-zero profile) while following a regime where elemental diffusion was not the limiting factor (flat profile); in this case, mass transfer was most likely limited by slow Li release to the efficient diffusive pathways, suggesting the existence in the host-rock of micro-domains with limited fluid availability, connected only intermittently to the pervasively fluid-filled porosity interconnected network; or (2) chemical diffusion proceeded until the chemical potential that drove diffusion vanished, leaving in the host-rock homogeneously distributed cookeite in chemical equilibrium with vein cookeite (i.e., with a similar solubility); such "stable cookeite" could be accounted for by the clusters of nicely stacked cookeite sheets and fibrous microveins observed in host-rocks.

Development of the chemical potential gradients that drove mass transfer to veins could be 
either stress-induced or interfacial energy driven, or a contribution of both. Indeed, this unusual selective transfer of phyllosilicates to veins could be due to the fact that they present the highest solubility variations with pressure, among Vanoise bauxite minerals (all Al-rich). In these rocks, phyllosilicates were thus the most sensitive to pressure-solution, whereas in more classical quartz-carbonate-bearing rocks, they are among the least soluble minerals and thus remain in the host-rock as residue. Mineral solubility variation with pressure seems to be the chief controlling parameter for pressure-solution creep. Although mass transfer to veins is considered to be mostly stress-induced in rocks submitted to a differential stress (Dewers and Hajash, 1995; Emmanuel et al., 2010), the contribution of interfacial energy processes (poresize controlled solubility and Ostwald ripening) may not be negligible in the almost undeformed Vanoise bauxites, as suggested by the selective transfer of anhedral microsheets of phyllosilicates only to veins. Such small crystals are likely to maintain high supersaturation levels in the small host-rock pores compared to veins, creating chemical potential gradients.

In both cases, cookeite preferential (over pyrophyllite) transfer to veins could be accounted for by faster monovalent $\mathrm{Li}$ diffusion compared to $\mathrm{Si}$ and $\mathrm{Al}$. The shift from cookeite to pyrophyllite transfer, although host-rocks were not completely cookeite-depleted, could reflect the onset of the retrograde P-T path (case 1): the decrease in pyrophyllite solubility with decreasing $\mathrm{P}$ and $\mathrm{T}$ may enhance its supersaturation and subsequent crystallization in veins, then favouring pyrophyllite (over cookeite) transfer. Fig. 8 is a synthesis of these observations and interpretations.

Finally, cookeite transfer to veins required the diffusion of important amounts of Al, which is often considered as a limiting parameter. Lithium, which is a strategic element for clean energy, was also observed to preferentially migrate and segregate into veins during metamorphic processes. This may be of importance for exploration purposes. 
Acknowledgments - The authors thank P. Mauchien and the Department of PhysicoChemistry (CEA Saclay) for allowing the LIBS analyses. R. Caron, D. Devaux and E. Delairis are acknowledged for making the thin and polished sections, and M. Moroni for some photographs. This work was funded by the programme 3F (INSU-CNRS) and ISTeP (UPMC) funds. BG thanks the OSU-Institut Pythéas. This paper benefited from fruitful and constructive comments provided by A. Tarantola and P. Goncalves, and editorial handling by Y. Rolland. 


\section{Appendix A - Quantification of LIBS data}

The main variability sources in LIBS analysis are:

- laser energy fluctuations with time (+/- 4\%);

- XY stepper motor precision, which is < $10 \%$ of displacement step (Menut et al., 2003), i.e., $<1 \mu \mathrm{m}$ in our case;

- the precision of laser focus on the sample surface, which highly depends on both flatness and horizontal position of the sample; for big rock slices, the focus was checked between each map analysis by means of a CCD camera placed above the microscope; both thin sections and rock slices were polished to ensure a better flatness of the sample, and a subsequent better analysis repeatability (Menut et al., 2003).

Quantification of LIBS emission spectra is problematic due to both physical (density, surface texture, granularity) and chemical (element concentration) matrix effects. Several analytical methodologies can be applied to retrieve chemical composition from LIBS spectra: (1) the classical calibration curve method (Sallé et al., 2006), which could ultimately be as accurate as electron microprobe (Fabre et al., 2002) but requires the use of matrix-matched standards; (2) the calibration-free method, based on modelling of the plasma physical parameters, which does not require the use of standards but has a lower accuracy (10-30\%, Palleschi et al., 1999) than calibration curve quantification, allowing only semi-quantitative analyses (Rossi et al., 2014); and (3) multivariate analyses, mainly used to calculate the composition of unknown samples by comparing them with reference sample spectra, and which robustness relies on the great number of spectra for many reference samples (McMillan et al., 2014; Cousin et al., 2015 ), therefore inappropriate in our case. The specific analytical setup used here (small laser shots to favour spatial resolution and use of low intensity lines for most elements) also precluded the use of the calibration free method.

Overcoming matrix effects for calibration-curve quantification of the Vanoise bauxite 
analyses was however particularly challenging, due to their strong chemical heterogeneity as well as physical heterogeneity (pure cookeite veins vs host-rocks). 10 bauxitic samples were used as standards to establish a calibration curve for host-rocks. Samples were ground (to overcome chemical heterogeneity), and the powder pressed into pellets to mimic the matrix of bauxitic rocks. For each standard, 500 analysis points were performed and averaged. Unfortunately, no calibration curve could be defined for Al, due to very similar Al contents for all samples. Although the calibration curve for Li was linear and passing through the origin (no self-absorption for low Li concentration, in agreement with the data of Fabre et al., 2002), analyses were too scattered to allow a reliable quantification. Similar linear tendency but even more scattered points were observed for $\mathrm{Fe}, \mathrm{Mg}$ and $\mathrm{Si}$, probably due to the use of a low intensity line for these elements. Therefore, the LIBS analysis of pressed powder pellets may be submitted to strong matrix effects. These scattered analytic points may also be due to the strong lateral variation in chemical composition of the Vanoise bauxites: although large samples were ground and the powder homogenised, the powder used for pellets may still have a composition slightly different from the powder used for chemical analyses. Li-rich pure minerals (spodumene, bikitaite, cooleite, petalite) were also analysed, but again, the results were too scattered to establish a calibration curve, reflecting important matrix effects. Therefore, no calibration curve could be used here. Moreover in our case, the analysis of oxygen and its use as an internal standard for normalization (Sallé et al., 2006) was precluded by the spectroscopic ranges selected for analyses.

Therefore, the LIBS analyses could not be satisfactorily quantified. However, the intensities of the LIBS analyses being similar over each profiles (Figs. 4-5), we used the chemical analyses of each host-rock to quantify precisely the Li content of the Vanoise samples. 


\section{Appendix B - Modelling of Li transfer between two cookeite veins.}

Modelling was made using a homemade Matlab code based on a 1D finite element method described in Crank (1975, p 142). Li diffuses within an aqueous fluid network, which connects veins and host-rock. A source term is added, which allows transferring Li from rock to the connected fluid network at a rate $\mathrm{k}^{\prime} .(1-\mathrm{Q} / \mathrm{K})$ where $\mathrm{k}^{\prime}$ is a rate constant (in mole of cookeite $/ \mathrm{cm}^{3}$ of cookeite / year) and $\mathrm{Q} / \mathrm{K}$ the saturation index in the aqueous solution. Cookeite reactive surface area is taken as constant (Wood and Walther, 1983) with cookeite fibres of $10 \mu \mathrm{m} \times 1 \mu \mathrm{m}$. The model considers a mean distance of $4 \mathrm{~cm}$ between two cookeite veins, and an initial Li content in the host-rock of $8.10^{-4}$ mol.cm ${ }^{-3}$ (mean value for studied bulk rocks, Table 3).

As explained in section 6.1 and Fig. 6, cookeite selective transfer to veins should result in Li chemical potential gradients between host-rock and veins, which will drive Li transfer. With this model, we calculated the proportion $(\mathrm{mol} \%)$ of initial host-rock Li content that would be transferred to veins in $1 \mathrm{Ma}$, considering different values for $\mathrm{Li}$ diffusion coefficients D (from $10^{-11.5}$ to $10^{-16} \mathrm{~m}^{2} \cdot \mathrm{s}^{-1}$ ) and dissolution kinetics $\mathrm{k}$ (from $10^{-9}$ to $10^{-4.5} \mathrm{~g} . \mathrm{cm}^{-}$ $\left.{ }^{2} \cdot \mathrm{y}^{-1}\right)$. Li concentration in the host-rock fluid was first taken as twice that in the vein fluid: $\mathrm{C}_{\mathrm{Li}}{ }^{\mathrm{HR}} / \mathrm{C}_{\mathrm{Li}}{ }^{\mathrm{V}}=2$, i.e., $\Delta \mathrm{rG}=4 \mathrm{~kJ}$ and $\mathrm{Q} / \mathrm{K}=2$, with $\mathrm{Q}$ and $\mathrm{K}$ the equilibrium constants of cookeite dissolution reaction at $360{ }^{\circ} \mathrm{C}-0.5 \mathrm{GPa}$ in host-rock and veins respectively. A hostrock porosity of $1 \%$ was considered.

To reach 50 mol\% of Li transfer to veins (mean host-rock depletion, Table 3) with final flat Li profiles (case 1, reaction-limited) requires $\mathrm{D} \geq 10^{-12}-10^{-13} \mathrm{~m}^{2} \cdot \mathrm{s}^{-1}$ for $\mathrm{k} \leq 10^{-7} \mathrm{~g} \cdot \mathrm{cm}^{-2} \cdot \mathrm{y}^{-1}$. Note that final flat Li profiles are considered when the ratio between the final remaining $\mathrm{Li}$ amount in the host-rock at mid-distance between two veins (i.e., $2 \mathrm{~cm}$ ) and in the vein vicinity is below $10 \mathrm{~mol} \%$. 


\section{Appendix C - Thermochemical calculation of fluid-mineral equilibrium}

Fluid-mineral equilibrium calculations were performed to determine the effect of temperature, pressure, and stress variations on the relative solubility of minerals, and to determine the sequence of minerals that would be consequently dissolved or crystallized, and potentially transferred to veins. Calculations were performed with the geochemical software ARXIM (developed by J. Moutte, Ecole des Mines de Saint-Etienne), using: the internally consistent thermodynamic database of Berman (1988) for mineral phases, completed by data for Fe-chloritoid (B.E. Patrick and R.G. Berman, unpubl. data) and cookeite (Vidal and Goffé, 1991); the HKF equations of Helgeson et al. (1981) and thermodynamic data of Shock et al. (1997) for aqueous phases. The formalism and validity of data for the aqueous species is limited to $0.5 \mathrm{GPa}$. Therefore, the calculations were made at $360{ }^{\circ} \mathrm{C}-0.5 \mathrm{GPa}$, although the peak metamorphic conditions are $360{ }^{\circ} \mathrm{C}-1.2 \mathrm{GPa}$. For this reason, and because the fluid composition may be more complex in natural metabauxites, these calculations do not pretend to be strictly quantitative for the Vanoise bauxites, but to give the sequence of dissolved / crystallized minerals in response to $\mathrm{P}$ and $\mathrm{T}$ changes.

Calculations were carried out to evaluate the impact of a $\mathrm{T}, \mathrm{P}$ or stress difference on the relative mineral solubility among the Vanoise bauxite minerals. Therefore, in each case, we calculated the composition of an initially pure $\mathrm{H}_{2} \mathrm{O}$ fluid in equilibrium with the metabauxite mineral assemblage (diaspore + cookeite + pyrophyllite + chloritoid + muscovite + paragonite) at $360^{\circ} \mathrm{C}-0.5 \mathrm{GPa}$, and compared it with the equilibrium fluid composition for a different $\mathrm{T}$ or $\mathrm{P}$, which allows calculation of the amount of mineral dissolved or crystallized in response to a $\mathrm{T}$ or $\mathrm{P}$ variation.

The general tendency is that the solubility increases with pressure for all the Vanoise bauxite minerals, so considering each mineral independently, one would conclude that all 
minerals would be dissolved in response to P increase or differential stress. On the contrary, calculations show that diaspore may rather crystallize in response to a $\mathrm{P}$ increase or differential stress. Indeed, the relative increase of aqueous Si and Li being a lot higher than aqueous $\mathrm{Al}\left(\sim 10^{-3}, 10^{-4}\right.$ and $10^{-7} \mathrm{~mol} / \mathrm{kg} \mathrm{H}_{2} \mathrm{O}$, respectively; Table 4), a $10 \mathrm{MPa}$ pressure increase implies dissolution of both pyrophyllite and cookeite (+ minor paragonite, muscovite and chloritoid; Table 4), and subsequent precipitation of diaspore (i.e., to store the excess $\mathrm{Al}$ released). Therefore, pyrophyllite and cookeite present the highest solubility variation with pressure. In response to temperature increase, the solubility of pyrophyllite increases, but that of cookeite and diaspore decreases, so a temperature increase would result in pyrophyllite dissolution and both diaspore and cookeite crystallization. 


\section{References}

Alcantar, N., Israelachvili, J., Boles, J., 2003. Forces and ionic transport between mica surfaces: implications for pressure solution. Geochimica et Cosmochimica Acta 67, 12891304. doi:10.1016/S0016-7037(02)01270-X

Austrheim, H., 1987. Eclogitization of lower crustal granulites by fluid migration through shear zones. Earth and Planetary Science Letters 81, 221-232. doi:10.1016/0012$821 X(87) 90158-0$

Bardossy, G., 1982. Karstbauxites: bauxite deposits on carbonate rocks. Developpments in Economic Geology 14.

Baxter, E.F., 2003. Natural constraints on metamorphic reaction rates. Geological Society, London, Special Publications 220, 183-202.

Baxter, E.F., DePaolo, D.J., 2002. Field measurement of high temperature bulk reaction rates I: Theory and technique. American Journal of Science 302, 442-464.

Bear, J., 1988. Dynamics of Fluids in Porous Media. Dover, New York.

Bebout, G.E., 2007. Metamorphic chemical geodynamics of subduction zones. Earth and Planetary Science Letters 260, 373-393. doi:10.1016/j.eps1.2007.05.050

Beitter, T., Wagner, T., Markl, G., 2008. Formation of kyanite-quartz veins of the Alpe Sponda, Central Alps, Switzerland: implications for Al transport during regional metamorphism. Contributions to Mineralogy and Petrology 156, 689-707. doi:10.1007/s00410-008-0310-4

Berman, R., 1988. Internally-consistent thermodynamic data for minerals in the system $\mathrm{Na}_{2} \mathrm{O}-$ $\mathrm{K}_{2} \mathrm{O}-\mathrm{CaO}-\mathrm{MgO}-\mathrm{FeO}-\mathrm{Fe}_{2} \mathrm{O}_{3}-\mathrm{Al}_{2} \mathrm{O}_{3}-\mathrm{SiO}_{2}-\mathrm{TiO}_{2}-\mathrm{H}_{2} \mathrm{O}-\mathrm{CO}_{2}$. Journal of Petrology 29, 445522. 
Berman, R. G., 1991. Thermobarometry using multi-equilibrium calculations - A new technique, with petrological applications. Canadian Mineralogist, 29, 833-855.

Berman, R. G., Brown, T. H. \& Perkins, E. H., 1987. GeO-Calc - Software for calculation and display of P-T-X phase-diagrams. American Mineralogist, 72, 861-862.

Bernard, S., Benzerara, K., Beyssac, O., Menguy, N., Guyot, F., Brown, G.E., Goffé, B., 2007. Exceptional preservation of fossil plant spores in high-pressure metamorphic rocks. Earth and Planetary Science Letters 262, 257-272. doi:10.1016/j.epsl.2007.07.041

Bons, P.D., Elburg, M.A., Gomez-Rivas, E., 2012. A review of the formation of tectonic veins and their microstructures. Journal of Structural Geology 43, 33-62. doi:10.1016/j.jsg.2012.07.005

Bos, B., Spiers, C.J., 2000. Effect of phyllosilicates on fluid-assisted healing of gouge-bearing faults. Earth and Planetary Science Letters 184, 199-210. doi:10.1016/S0012$821 X(00) 00304-6$

Boutoux, A., Verlaguet, A., Bellahsen, N., Lacombe, O., Villemant, B., Caron, B., Martin, E., Assayag, N., Cartigny, P., 2014a. Fluid systems above basement shear zones during inversion of pre-orogenic sedimentary basins (External Crystalline Massifs, Western Alps). Lithos 206-207, 435-453. doi:10.1016/j.lithos.2014.07.005

Boutoux, A., Bellahsen, N., Lacombe, O., Verlaguet, A., Mouthereau, F., 2014b. Inversion of pre-orogenic extensional basins in the external Western Alps: Structure, microstructures and restoration. Journal of Structural Geology 60, 13-29. doi:10.1016/j.jsg.2013.12.014

Carlson, W.D., 2010. Dependence of reaction kinetics on $\mathrm{H}_{2} \mathrm{O}$ activity as inferred from rates of intergranular diffusion of aluminium: reaction kinetics and aluminium diffusion. Journal of Metamorphic Geology no-no. doi:10.1111/j.1525-1314.2010.00886.x

Carmichael, D.M., 1969. On the mechanism of prograde metamorphic reactions in quartzbearing pelitic rocks. Contributions to Mineralogy and Petrology 20, 244-267. 
Cesare, B., 1994. Synmetamorphic veining - origin of andalusite-bearing veins in the Vedrette-di-Ries contact aureole, eastern alps, Italy. Journal of Metamorphic Geology 12, 643-653. doi:10.1111/j.1525-1314.1994.tb00048.x

Cousin, A., Meslin, P.Y., Wiens, R.C., Rapin, W., Mangold, N., Fabre, C., Gasnault, O., Forni, O., Tokar, R., Ollila, A., Schroeder, S., Lasue, J., Maurice, S., Sautter, V., Newsom, H., Vaniman, D., Le Mouelic, S., Dyar, D., Berger, G., Blaney, D., Nachon, M., Dromart, G., Lanza, N., Clark, B., Clegg, S., Goetz, W., Berger, J., Barraclough, B., Delapp, D., 2015. Compositions of coarse and fine particles in martian soils at gale: A window into the production of soils. Icarus 249, 22-42. doi:10.1016/j.icarus.2014.04.052

Crank, J., 1975. The mathematics of diffusion. Clarendon Press, Oxford.

Croizé, D., Renard, F., Bjørlykke, K., Dysthe, D.K., 2010. Experimental calcite dissolution under stress: Evolution of grain contact microstructure during pressure solution creep. Journal of Geophysical Research 115. doi:10.1029/2010JB000869

Dewers, T., Hajash, A., 1995. Rate laws for water-assisted compaction and stress-induced water-rock interaction in sandstones. Journal of Geophysical Research-Solid Earth 100, 13093-13112. doi:10.1029/95JB00912

Dewers, T., Ortoleva, P., 1990. Differentiated structures arising from mechanochemical feedback in stressed rocks. Earth-Science Reviews 29, 283-298. doi:10.1016/00128252(0)90043-U

Diamond L.W., Tarantola A., 2015. Interpretation of fluid inclusions in quartz deformed by weak ductile shearing: Reconstruction of differential stress magnitude and pre-deformation fluid properties. Earth and Planetary Science Letters 417, 107-119. doi:10.1016/j.epsl.2015.02.019

Ellenberger, F., 1958. Etude géologique du pays de Vanoise, Mémoire explicatif de la carte géologique de France. 
Emmanuel, S., Ague, J.J., Walderhaug, O., 2010. Interfacial energy effects and the evolution of pore size distributions during quartz precipitation in sandstone. Geochimica et Cosmochimica Acta 74, 3539-3552. doi:10.1016/j.gca.2010.03.019

Emmanuel, S., Berkowitz, B., 2007. Effects of pore-size controlled solubility on reactive transport in heterogeneous rock. Geophysical Research Letters 34. doi:10.1029/2006GL028962

Etheridge, M.A., 1983. Differential stress magnitudes during regional deformation and metamorphism: upper bound imposed by tensile fracturing. Geology 11, 231-234. doi: 10.1130/0091-7613(1983)11<231:DSMDRD>2.0.CO;2

Fabre, C., Boiron, M.C., Dubessy, J., Chabiron, A., Charoy, B., Crespo, T.M., 2002. Advances in lithium analysis in solids by means of laser-induced breakdown spectroscopy: An exploratory study. Geochimica Et Cosmochimica Acta 66, 1401-1407. doi:10.1016/S0016-7037(01)00858-4

Fabre, C., Maurice, S., Cousin, A., Wiens, R.C., Forni, O., Sautter, V., Guillaume, D., 2011. Onboard calibration igneous targets for the Mars Science Laboratory Curiosity rover and the Chemistry Camera laser induced breakdown spectroscopy instrument. Spectrochimica Acta Part B: Atomic Spectroscopy 66, 280-289. doi:10.1016/j.sab.2011.03.012

Farver, J., Yund, R., 2000. Silicon diffusion in a natural quartz aggregate: constraints on solution-transfer diffusion creep. Tectonophysics 325, 193-205.

Feenstra, A., Ockenga, E., Rhede, D., Wiedenbeck, M., 2003. Li-rich zincostaurolite and its decompression-related breakdown products in a diaspore-bearing metabauxite from East Samos (Greece): An EMP and SIMS study. American Mineralogist 88, 789-805.

Fisher, D., Brantley, S., 1992. Models of quartz overgrowth and vein formation- Deformation and episodic fluid flow in an ancient subduction zone. Journal of Geophysical Research 97, 20-043. 
Fisher, D., Brantley, S., Everett, M., Dzvonik, J., 1995. Cyclic fluid-flow through a regionally extensive fracture network within the Kodiak accretionary prism. Journal of Geophysical Research-Solid Earth 100, 12881-12894. doi:10.1029/94JB02816

Fletcher, R.C., Merino, E., 2001. Mineral growth in rocks: kinetic-rheological models of replacement, vein formation, and syntectonic crystallization. Geochimica et Cosmochimica Acta, 65(21), 3733-3748. doi: 10.1016/S0016-7037(01)00726-8

Gardès, E., Wunder, B., Marquardt, K., Heinrich, W., 2012. The effect of water on intergranular mass transport: new insights from diffusion-controlled reaction rims in the $\mathrm{MgO}-\mathrm{SiO} 2$ system. Contributions to Mineralogy and Petrology 164, 1-16. doi:10.1007/s00410-012-0721-0

Goffé, B., 1977. Occurrence of cookeite in metamorphic bauxites of Dogger from Vanoise (Savoie). Bulletin de la Société Française de Minéralogie et de Cristallographie 100(5), 254-257.

Goffé, B., 1982. Définition du faciès à Fe-Mg carpholite - chloritoide, un marqueur du métamorphisme de HP-BT dans les métasédiments alumineux (Thèse de Doctorat d'Etat). Université Pierre et Marie Curie, Paris 6, France.

Goffé, B., Murphy, W.M., Lagache, M., 1987. Experimental transport of Si, Al and Mg in hydrothermal solutions: an application to vein mineralization during high-pressure, lowtemperature metamorphism in the French Alps. Contributions to Mineralogy and Petrology $97,438-450$.

Goffé, B., Schwartz, S., Lardeaux, J.-M., Bousquet, R., 2004. Explanatory notes to the map: metamorphic structure of the Alps - Western and Ligurian Alps. Mitteilungen der Osterreichischen Mineralogischen Gesellschaft 149, 125-144.

Goffé, B., Vidal, O., 1992. Evidence for the controlling effect of the high pressure metamorphic PTt path on the mass transfer of major elements, in: Proceedings of the 
Seventh International Symposium on Water-Rock Interaction. Balkema, Rotterdam, pp. $1499-1502$.

Gratier, J.P., Guiguet, R., 1986. Experimental pressure solution deposition on quartz grains the crucial effect of the nature of the fluid. Journal of Structural Geology 8, 845-856. doi:10.1016/0191-8141(86)90030-1

Gratier, J.P., Vialon, P., 1980. Deformation pattern in a heterogeneous material - folded and cleaved sedimentary cover immediately overlying a crystalline basement (Oisans, French Alps). Tectonophysics 65, 151-180. doi:10.1016/0040-1951(80)90228-0

Greene, G.W., Kristiansen, K., Meyer, E.E., Boles, J.R., Israelachvili, J.N., 2009. Role of electrochemical reactions in pressure solution. Geochimica et Cosmochimica Acta 73, 2862-2874. doi:10.1016/j.gca.2009.02.012

Gueydan, F., Leroy, Y.M., Jolivet, L., 2004. Mechanics of low-angle extensional shear zones at the brittle-ductile transition. Journal of Geophysical Research-Solid Earth 109, B12407. doi:10.1029/2003JB002806

Helgeson, H.C., Kirkham, D., Flowers, G., 1981. Theoretical prediction of the thermodynamic behavior of aqueous-electrolytes at high-pressures and temperatures .4. calculation. American Journal of Science 281, 1249-1516.

Hilgers, C., Urai, J.L., 2005. On the arrangement of solid inclusions in fibrous veins and the role of the crack-seal mechanism. Journal of Structural Geology, 27(3), 481-494. doi: 10.1016/j.jsg.2004.10.012

Jaboyedoff, M., Thelin, P., 1996. New data on low-grade metamorphism in the Brianconnais domain of the Prealps, Western Switzerland. European Journal of Mineralogy 8, 577-592.

John, T., Gussone, N., Podladchikov, Y.Y., Bebout, G.E., Dohmen, R., Halama, R., Klemd, R., Magna, T., Seitz, H-M., 2012. Volcanic arcs fed by rapid pulsed fluid flow through subducting slabs. Nature Geoscience 5, 489-492. doi:10.1038/ngeo1482 
Jolivet, L., Faccenna, C., Goffé, B., Mattei, M., Rossetti, F., Brunet, C., Storti, F., Funiciello, R., Cadet, J.-P., Parra, T., 1998. Midcrustal shear zones in post-orogenic extension: the Northern Tyrrhenian Sea case. Journal of Geophysical Research 103, 12123-12160.

Jullien, M., Baronnet, A., Goffe, B., 1996. Ordering of the stacking sequence in cookeite with increasing pressure: An HRTEM study. American Mineralogist 81, 67-78.

Kelly, E.D., Carlson, W.D., Ketcham, R.A., 2013. Crystallization kinetics during regional metamorphism of porphyroblastic rocks. Journal of Metamorphic Geology 31, 963-979. doi:10.1111/jmg.12052

Kirschner, D.L., Sharp, Z.D., Masson, H., 1995. Oxygen isotope thermometry of quartzcalcite veins: Unraveling the thermal-tectonic history of the subgreenschist facies Morcles nappe (Swiss Alps). Geological Society of America Bulletin 107, 1145-1156.

Kowacz, M., Putnis, A., 2008. The effect of specific background electrolytes on water structure and solute hydration: Consequences for crystal dissolution and growth. Geochimica et Cosmochimica Acta 72, 4476-4487. doi:10.1016/j.gca.2008.07.005

Kristiansen, K., Valtiner, M., Greene, G.W., Boles, J.R., Israelachvili, J.N., 2011. Pressure solution - The importance of the electrochemical surface potentials. Geochimica et Cosmochimica Acta 75, 6882-6892. doi:10.1016/j.gca.2011.09.019

Marquer, D., Burkhard, M., 1992. Fluid circulation, progressive deformation and masstransfer processes. Journal of Structural Geology 14, 1047-1057. doi:10.1016/01918141(92)90035-U

Maurice, S. et al., 2012. The ChemCam instrument Suite on the Mars Science Laboratory (MSL) Rover: Science Objectives and Mast Unit Description. Space Science Reviews 170 (1-4), 95-166. 
McMillan, N.J., Rees, S., Kochelek, K., McManus, C., 2014. Geological Applications of Laser-Induced Breakdown Spectroscopy. Geostandards and Geoanalytical Research 38, 329-343. doi:10.1111/j.1751-908X.2014.00308.x

Means, W.D., Li, T., 2001. A laboratory simulation of fibrous veins: some first observations. Journal of Structural Geology, 23(6-7), 857-863. doi: 10.1016/S0191-8141(00)00158-9

Menut, D., Fichet, P., Lacour, J.L., Rivoallan, A., Mauchien, P., 2003. Micro-laser-induced breakdown spectroscopy technique: a powerful method for performing quantitative surface mapping on conductive and nonconductive samples. Applied Optics 42, 6063-6071. doi:10.1364/AO.42.006063

Meyer, E.E., Greene, G.W., Alcantar, N.A., Israelachvili, J.N., Boles, J.R., 2006. Experimental investigation of the dissolution of quartz by a muscovite mica surface: Implications for pressure solution. Journal of Geophysical Research-Solid Earth 111, B08202. doi:10.1029/2005JB004010

Moenke-Blankenburg, 1989. Laser Micro Analysis, New York. ed. Willey.

Monié, P., 1990. Preservation of hercynian ar-40/ar-39 ages through high-pressure lowtemperature alpine metamorphism in the western alps. European Journal of Mineralogy 2, $343-361$.

Moore, D.E., Rymer, M.J., 2007. Talc-bearing serpentinite and the creeping section of the San Andreas fault. Nature 448, 795-797. doi:10.1038/nature06064

Nakamura, M., Watson, E.B., 2001. Experimental study of aqueous fluid infiltration into quartzite: implications for the kinetics of fluid redistribution and grain growth driven by interfacial energy reduction. Geofluids $1,73-89$.

Nenna, F., Aydin, A., 2011. The formation and growth of pressure solution seams in clastic rocks: A field and analytical study. Journal of Structural Geology 33, 633-643. doi:10.1016/j.jsg.2011.01.014 
Newton, R.C., Manning, C.E., 2003. Activity coefficient and polymerization of aqueous silica at $800^{\circ} \mathrm{C}, 12 \mathrm{kbar}$, from solubility measurements on $\mathrm{SiO}_{2}$-buffering mineral assemblages. Contributions to Mineralogy and Petrology 146, 135-143. doi:10.1007/s00410-003-0483-9

Niemeijer, A., Marone, C., Elsworth, D., 2010. Frictional strength and strain weakening in simulated fault gouge: Competition between geometrical weakening and chemical strengthening. Journal of Geophysical Research-Solid Earth 115, B10207. doi:10.1029/2009JB000838

Oelkers, E., Helgeson, H.C., 1988. Calculation of the thermodynamic and transport-properties of aqueous species at high-pressures and temperatures - aqueous tracer diffusioncoefficients of ions to $1000{ }^{\circ} \mathrm{C}$ and $5 \mathrm{~kb}$. Geochimica Et Cosmochimica Acta 52, 63-85. doi:10.1016/0016-7037(88)90057-9

Oliver, N.H.S., Bons, P.D., 2001. Mechanisms of fluid flow and fluid-rock interaction in fossil metamorphic hydrothermal systems inferred from vein-wallrock patterns, geometry and microstructure. Geofluids 1, 137-162. doi:10.1046/j.1468-8123.2001.00013.x

Palleschi, V., Ciucci, A., Rastelli, S., Tognoni, E., 1999. Method for quantitative analysis of atomic components of materials by LIBS spectroscopy measurements. WO99/49301.

Penniston-Dorland, S.C., Bebout, G.E., Pogge von Strandmann, P.A.E., Elliott, T., Sorensen, S.S., 2012. Lithium and its isotopes as tracers of subduction zone fluids and metasomatic processes: Evidence from the Catalina Schist, California, USA. Geochimica et Cosmochimica Acta 77, 530-545. doi:10.1016/j.gca.2011.10.038

Penniston-Dorland, S.C., Sorensen, S.S., Ash, R.D., Khadke, S.V., 2010. Lithium isotopes as a tracer of fluids in a subduction zone mélange: Franciscan Complex, CA. Earth and Planetary Science Letters 292, 181-190. doi:10.1016/j.eps1.2010.01.034 
Poinssot, C., Goffe, B., Toulhoat, P., 1997. Geochemistry of the Triassic-Jurassic Alpine continental deposits: Origin and geodynamic implications. Bulletin De La Société Géologique De France 168, 287-300.

Pokrovskii, V.A., Helgeson, H.C., 1997. Thermodynamic properties of aqueous species and the solubilities of minerals at high pressures and temperatures: The system $\mathrm{Al}_{2} \mathrm{O}_{3}-\mathrm{H}_{2} \mathrm{O}-$ KOH. Chemical Geology 137, 221-242. doi:10.1016/S0009-2541(96)00167-2

Putnis, A., 2009. Mineral Replacement Reactions. Reviews in Mineralogy and Geochemistry 70, 87-124. doi:10.2138/rmg.2009.70.3

Putnis, A., 2002. Mineral replacement reactions: from macroscopic observations to microscopic mechanisms. Mineralogical Magazine 66, 689-708. doi:10.1180/0026461026650056

Putnis, A., Mauthe, G., 2001. The effect of pore size on cementation in porous rocks. Geofluids 1, 37-41. doi:10.1046/j.1468-8123.2001.11001.x

Putnis, A., Prieto, M., Fernandez, L., 1995. Fluid supersaturation and crystallization in porous-media. Geological Magazine 132, 1-13.

Ramsey, J.M., Chester, F.M., 2004. Hybrid fracture and the transition from extension fracture to shear fracture. Nature 428 (6978), 63-66. doi:10.1038/nature02333

Renard, F., Ortoleva, P., 1997. Water films at grain-grain contacts: Debye-Huckel, osmotic model of stress, salinity, and mineralogy dependence. Geochimica Et Cosmochimica Acta 61, 1963-1970. doi:10.1016/S0016-7037(97)00036-7

Renard, F., Ortoleva, P., Gratier, J.P., 1997. Pressure solution in sandstones: influence of clays and dependence on temperature and stress. Tectonophysics 280, 257-266. doi:10.1016/S0040-1951(97)00039-5 
Rijniers, L.A., Huinink, H.P., Pel, L., Kopinga, K., 2005. Experimental Evidence of Crystallization Pressure inside Porous Media. Physical Review Letters 94. doi:10.1103/PhysRevLett.94.075503

Rimmelé, G., Oberhänsli, R., Goffé, B., Jolivet, L., Candan, O., Çetinkaplan, M., 2003. First evidence of high-pressure metamorphism in the "Cover Series" of the southern Menderes Massif. Tectonic and metamorphic implications for the evolution of SW Turkey. Lithos 71, 19-46. doi:10.1016/S0024-4937(03)00089-6

Rolland, Y., Cox, S., Boullier, A.-M., Pennacchioni, G., Mancktelow, N., 2003. Rare earth and trace element mobility in mid-crustal shear zones: insights from the Mont Blanc Massif (Western Alps). Earth and Planetary Science Letters 214, 203-219. doi:10.1016/S0012-821X(03)00372-8

Rossi, M., Dell'Aglio, M., De Giacomo, A., Gaudiuso, R., Senesi, G.S., De Pascale, O., Capitelli, F., Nestola, F., Ghiara, M.R., 2014. Multi-methodological investigation of kunzite, hiddenite, alexandrite, elbaite and topaz, based on laser-induced breakdown spectroscopy and conventional analytical techniques for supporting mineralogical characterization. Physics and Chemistry of Minerals 41, 127-140. doi:10.1007/s00269013-0631-3

Rubie, D.C., 1986. The catalysis of mineral reactions by water and restrictions on the presence of aqueous fluid during metamorphism. Mineralogical Magazine 50, 399-415. doi:10.1180/minmag.1986.050.357.05

Rutter, E., 1983. Pressure solution in nature, theory and experiment. Journal of the Geological Society 140, 725-740. doi:10.1144/gsjgs.140.5.0725

Rutter, E., 1976. Kinetics of rock deformation by pressure solution. Philosophical Transactions of the Royal Society a-Mathematical Physical and Engineering Sciences 283, 203-219. doi:10.1098/rsta.1976.0079 
Sallé, B., Lacour, J-L., Mauchien, P., Fichet, P., Maurice, S., Manhès, G., 2006. Comparative study of different methodologies for quantitative rock analysis by Laser-Induced Breakdown Spectroscopy in a simulated Martian atmosphere. Spectrochimica Acta Part B: Atomic Spectroscopy 61, 301-313. doi:10.1016/j.sab.2006.02.003

Sautter, V., Fabre, C., Forni, O., Toplis, M.J., Cousin, A., Ollila, A.M., Meslin, P.Y., Maurice, S., Wiens, R.C., Baratoux, D., Mangold, N., Le Mouélic, S., Gasnault, O., Berger, G., Lasue, J., Anderson, R.A., Lewin, E., Schmidt, M., Dyar, D., Ehlmann, B.L., Bridges, J., Clark, B., Pinet, P., 2014. Igneous mineralogy at Bradbury Rise: The first ChemCam campaign at Gale crater: IGNEOUS MINERALOGY AT BRADBURY RISE. Journal of Geophysical Research: Planets 119, 30-46. doi:10.1002/2013JE004472

Scherer, G.W., 2004. Stress from crystallization of salt. Cement and Concrete Research 34, 1613-1624. doi:10.1016/j.cemconres.2003.12.034

Shimizu, I., 1995. Kinetics of pressure solution creep in quartz - theoretical considerations. Tectonophysics 245, 121-134. doi:10.1016/0040-1951(94)00230-7

Shock, E.L., Sassani, D.C., Willis, M., Sverjensky, D.A., 1997. Inorganic species in geologic fluids: Correlations among standard molal thermodynamic properties of aqueous ions and hydroxide complexes. Geochimica Et Cosmochimica Acta 61, 907-950. doi:10.1016/S0016-7037(96)00339-0

Spandler, C., Pettke, T., Rubatto, D., 2011. Internal and External Fluid Sources for Eclogitefacies Veins in the Monviso Meta-ophiolite, Western Alps: Implications for Fluid Flow in Subduction Zones. Journal of Petrology 52, 1207-1236. doi:10.1093/petrology/egr025

Steefel, C., VanCappellen, P., 1990. A new kinetic approach to modeling water-rock interaction - the role of nucleation, precursors, and ostwald ripening. Geochimica Et Cosmochimica Acta 54, 2657-2677. doi:10.1016/0016-7037(90)90003-4 
Stunitz, H., 1998. Syndeformational recrystallization-dynamic or compositionally induced? Contributions to Mineralogy and Petrology 131, 219-236.

Sweetapple, M.T., Tassios, S., 2015. Laser-induced breakdown spectroscopy (LIBS) as a tool for in situ mapping and textural interpretation of lithium in pegmatite minerals. American Mineralogist 100, 2141-2151. doi:10.2138/am-2015-5165

Taber, S., 1916. The growth of crystals under external pressure. American Journal of Science 41(246), 532-556

Tada, R., Maliva, R., Siever, R., 1987. A new mechanism for pressure solution in porous quartzose sandstone. Geochimica Et Cosmochimica Acta 51, 2295-2301. doi:10.1016/0016-7037(87)90282-1

Tada, R., Siever, R., 1989. Pressure solution during diagenesis. Annual Review of Earth and Planetary Sciences 17, 89.

van Noort, R., Spiers, C.J., Peach, C.J., 2011. Structure and properties of loaded silica contacts during pressure solution: impedance spectroscopy measurements under hydrothermal conditions. Physics and Chemistry of Minerals 38, 501-516. doi:10.1007/s00269-011-0423-6

Verlaguet, A., Brunet, F., 2007. Effect of incongruent dissolution on mineral solubility data derived from quench experiments. European Journal of Mineralogy 19, 783-789. doi:10.1127/0935-1221/2007/0019-1772

Verlaguet, A., Brunet, F., Goffé, B., Murphy, W.M., 2006. Experimental study and modeling of fluid reaction paths in the quartz-kyanite \pm muscovite-water system at $0.7 \mathrm{GPa}$ in the 350-550 ${ }^{\circ} \mathrm{C}$ range: Implications for $\mathrm{Al}$ selective transfer during metamorphism. Geochimica et Cosmochimica Acta 70, 1772-1788. doi:10.1016/j.gca.2005.12.014

Verlaguet, A., Goffé, B., Brunet, F., Poinssot, C., Vidal, O., Findling, N., Menut, D., 2011. Metamorphic veining and mass transfer in a chemically closed system: a case study in 
Alpine metabauxites (western Vanoise): metamorphic veining and mass transfer (Alps). Journal of Metamorphic Geology 29, 275-300. doi:10.1111/j.1525-1314.2010.00918.x

Vidal, O., Goffé, B., 1991. Cookeite $\mathrm{LiAl}_{4}\left(\mathrm{Si}_{3} \mathrm{Al}\right) \mathrm{O}_{10}(\mathrm{OH})_{8}$ : Experimental study and thermodynamical analysis of its compatibility relations in the $\mathrm{Li}_{2} \mathrm{O}-\mathrm{Al}_{2} \mathrm{O}_{3}-\mathrm{SiO}_{2}-\mathrm{H}_{2} \mathrm{O}$ system. Contributions to Mineralogy and Petrology 108, 72-81.

Vidal, O., De Andrade, V., Lewin, E., Munoz, M., Parra, T. \& Pascarelli, S., 2006. P-Tdeformation- $\mathrm{Fe}^{3+} / \mathrm{Fe}^{2+}$ mapping at the thin section scale and comparison with XANES

mapping: application to a garnet-bearing metapelite from the Sambagawa metamorphic belt (Japan). Journal of Metamorphic Geology, 24, 669-683.

Vidal, O., Goffé, B. \& Theye, T., 1992. Experimental study of the stability of sudoïte and magnesiocarpholite and calculation of a petrogenetic grid for the system $\mathrm{FeO}-\mathrm{MgO}-\mathrm{Al}_{2} \mathrm{O}_{3^{-}}$ $\mathrm{SiO}_{2}-\mathrm{H}_{2} \mathrm{O}$. Journal of Metamorphic Geology, 10, 603-614.

Vidal, O., Parra, T. \& Trotet, F., 2001. A thermodynamic model for Fe-Mg aluminous chlorite using data from phase equilibrium experiments and natural pelitic assemblages in the 100 degrees to 600 degrees C, 1 to $25 \mathrm{~kb}$ range. American Journal of Science, 301, 557-592.

Vidal, O., Parra, T. \& Vieillard, P., 2005. Thermodynamic properties of the Tschermak solid solution in Fe-chlorite: application to natural examples and possible role of oxidation. American Mineralogist, 90, 347-358.

Walther, J., Orville, P., 1982. Volatile production and transport in regional metamorphism. Contributions to Mineralogy and Petrology 79, 252-257. doi:10.1007/BF00371516

Wassmann, S., Stöckhert, B., 2013. Rheology of the plate interface - Dissolution precipitation creep in high pressure metamorphic rocks. Tectonophysics 608, 1-29. doi:10.1016/j.tecto.2013.09.030 
Watson, E.B., Wark, D.A., 1997. Diffusion of dissolved $\mathrm{SiO} 2$ in $\mathrm{H} 2 \mathrm{O}$ at $1 \mathrm{GPa}$, with implications for mass transport in the crust and upper mantle. Contributions to Mineralogy and Petrology 130, 66-80. doi:10.1007/s004100050350

Weyl, P., 1959. Pressure solution and the force of crystallization - a phenomenological theory. Journal of Geophysical Research 64, 2001-2025. doi:10.1029/JZ064i011p02001

Widmer, T., Thompson, A.B., 2001. Local origin of high pressure vein material in eclogite facies rocks of the Zermatt-Saas Zone, Switzerland. American Journal of Science 301, $627-656$.

Wiltschko, D.V., Morse, J.W., 2001. Crystallization pressure versus "crack-seal" as the mechanism for banded veins. Geology, 29(1), 79-82. doi: 10.1130/00917613(2001)029<0079:CPVCSA>2.0.CO;2

Wintsch, R.P., 1985. The possible effects of deformation on chemical processes in metamorphic fault zones, in: Thompson, A.B., Rubie, D.C. (Eds.), Metamorphic Reaction Kinetics, Textures and Deformation, Advances in Physical Geochemistry. Springer-Verlag, New York, pp. 251-268.

Wintsch, R.P., Dunning, J., 1985. The effect of dislocation density on the aqueous solubility of quartz and some geologic implications - a theoretical approach. Journal of Geophysical Research-Solid Earth and Planets 90, 3649-3657. doi:10.1029/JB090iB05p03649

Wintsch, R.P., Yi, K., 2002. Dissolution and replacement creep: a significant deformation mechanism in mid-crustal rocks. Journal of Structural Geology 24, 1179-1193.

Wood, B., Walther, J., 1983. Rates of hydrothermal reactions. Science 222, 413-415. doi:10.1126/science.222.4622.413

Yalçin, Ü., Schreyer, W., Medenbach, O., 1993. Zn-rich högbomite formed from gahnite in the metabauxites of the Menderes Massif, SW Turkey. Contributions to Mineralogy and Petrology 113, 314-324. 
Yardley, B., Bottrell, S., 1992. Silica mobility and fluid movement during metamorphism of the connemara schists, ireland. Journal of Metamorphic Geology 10, 453-464. doi:10.1111/j.1525-1314.1992.tb00096.x 


\section{Figure captions}

Figure 1. Geographic localization and metamorphic P-T path of Vanoise metabauxites.

A- Simplified metamorphic map of the western Alps with localization and P-T metamorphic conditions of karstic bauxite outcrops (Briançonnais stratigraphic unit); modified after the Commission for the Geological Map of the World (Goffé et al., 2004). B- Metamorphic peak conditions (grey box) underwent by the western Vanoise bauxites and relative amount of fluid produced by the successive dehydration reactions, expressed as a vol\% of the bulk amount of fluid $\left(\mathrm{V}_{\mathrm{H} 2 \mathrm{O}} \mathrm{lib}=13 \%\right.$ of Vrock) produced along the prograde $\mathrm{P}-\mathrm{T}$ path (red dashed arrow); schemes (each illustrated by a sample picture) illustrate the relative chronology of the successive vein formation versus the main reactions (numbered 1 to 4 ) that occurred in the rock during metamorphism: chloritoid veins are synchronous with the chloritoid-in dehydration reaction (c, point 3) and are then crosscut by cookeite veins (fibrous generation preceding the formation of euhedral cookeite sheets, between point 3 and 4), in the centre of which a later generation of chlorite and/or pyrophyllite crystallized at the onset of the retrograde path (point 4); the peak metamorphic assemblage is composed of chloritoid + diaspore + pyrophyllite + cookeite + hematite + rutile + muscovite + paragonite; reaction a: $20 \mathrm{Carph} \rightarrow 4 \mathrm{Chl}+18 \mathrm{Dsp}+7 \mathrm{Prl}+8 \mathrm{H}_{2} \mathrm{O}$; reaction b: 4 Carph $+2 \mathrm{Dsp} \rightarrow 4 \mathrm{Cld}+\mathrm{Prl}+4$ $\mathrm{H}_{2} \mathrm{O}$; metamorphic reactions were calculated using the program PTAX, an extension of the GEO-CALC software (Berman et al., 1987); the internally consistent thermodynamic database of Berman (1988) was completed by thermodynamic data for Mg-carpholite (Vidal et al., 1992), chloritoid (B.E. Patrick and R.G. Berman, unpubl. data) and cookeite (Vidal and Goffé, 1991); cookeite-in reactions from bikitaite and spodumene (Vidal and Goffé, 1991); equilibrium P-T conditions of chlorite formation ( point 4) estimated from the composition of chlorite in the chlorite + diaspore $+\mathrm{H}_{2} \mathrm{O}$ assemblage, using a multiequilibrium technique with the software Tweeq (Berman, 1991) and the solution model and mixing properties from Vidal 
et al. (2001, 2005, 2006) for chlorite endmembers; this figure was modified after Verlaguet et al. (2011), in which details about the calculations can be found; Dsp: diaspore; Kln: kaolinite; Prl: pyrophyllite; Chl: chlorite; Carph: carpholite; Cld: chloritoid; Cook: cookeite; Ms: muscovite; Pg: paragonite; Qtz: quartz; Ky: kyanite; Hem: hematite; Rt: rutile.

Figure 2. Cookeite and pyrophyllite veins from Vanoise metabauxites. A-pure cookeite (Cook) vein showing a first generation of fibrous growth followed by euhedral growth; a fragment of host-rock was isolated during the vein formation and is now included in the median plane of the vein; B- C- a first generation (labelled 1) of fibrous cookeite grew symmetrically on both vein sides, followed by syntaxial growth of euhedral fan-shaped cookeite crystals (labelled 2) seeded on the first generation of cookeite fibres; a later generation (labelled 3) of pyrophyllite ( $\mathrm{Prl}$ ) forms euhedral crystals stacked into vermicular structures, in the median plane of cookeite veins (labelled 3); these veins exhibit irregular walls with multiple fibrous terminations that recall coalescent fibrous en-echelon veins (D); D- en-echelon fibrous cookeite veins that tend to connect to each other when they reach 2-3 $\mathrm{cm}$ and enclose host-rock fragments, giving rise to sigmoid host-rock inclusions similar to that in A; E- pure cookeite vein showing a first generation of fibres (1) that grew in an oblique direction from the vein walls (i.e., restricted opening of the vein walls), symmetrically on both vein sides, followed by syntaxial crystallization of euhedral fan-shaped crystals of cookeite (2), again symmetrical on both vein sides, recording growth in a fluid-filled open space; Fcookeite (on vein walls) and pyrophyllite (in the median plane) vein; G- fibrous cookeite microvein cross-cutting (thus post-dating) chloritoid crystals; H- micropod and microvein of fibrous cookeite in the host-rock; I- shear vein of pyrophyllite with dismembered chloritoid crystals, formed in a Li-poor rock thus devoid of cookeite veins; photographs (A-B-D-E-F), crossed-polars photomicrograph (C), BSE-SEM images (G-H-I). 
Figure 3. Typical emission spectra and chemical elementary maps obtained by LIBS analysis of a Vanoise bauxite sample. The laser generated plasma emission signal is analysed by two spectrometers (20 nm spectral range each) centred A- on emission line 670 $\mathrm{nm}$, allowing analysis of the most intense line of $\mathrm{Li}$; B- on emission line $388 \mathrm{~nm}$, allowing analysis of two intense emission lines for $\mathrm{Al}$, but only low intensity lines for $\mathrm{Si}, \mathrm{Mg}$ and $\mathrm{Fe}$; arrows indicate wavelength of the emission lines for each considered element. C- $1 \mathrm{~mm}^{2}$ chemical maps (grey scale), composed of 2,500 individual laser shots (50 x 50) of $10 \mu \mathrm{m}$ diameter, every $10 \mu \mathrm{m}$ in both directions; $\mathrm{Mg}$ (and $\mathrm{Fe}$ ) high intensity draw chloritoid crystal contours, but $\mathrm{Fe}$ is also present in hematite; Li high intensity reflects cookeite-rich zones; $\mathrm{Al}$ and Si intensities are more diffuse as they are present in most of the Vanoise minerals.

Figure 4. LIBS profiles of host-rock composition of external Alps samples. Profiles of 1 $\mathrm{mm}^{2}$ chemical maps, spaced by $1 \mathrm{~mm}$, performed across thin sections of representative samples of the external Alps bauxites (protolith of the Vanoise metabauxites); element intensities (in arbitrary unit) correspond to the mean intensity of the 2,500 laser shots composing each map (see text for background correction); A- DR7803: contains numerous rounded pisoids concentrating Al-hydroxides and Al-rich clay minerals; B- DR7807; CDR95A5: green/red colours suggest variations in oxidation degree; sample crosscut by diaspore + Al-berthierine veins); the flat Li profiles suggest an even distribution of Li in the sedimentary protolith.

Figure 5. LIBS profiles of host-rock composition between cookeite veins in the Vanoise metabauxites. Profiles of $1 \mathrm{~mm}^{2}$ chemical maps, spaced by $1 \mathrm{~mm}$, performed across samples perpendicular to cookeite veins; element intensities (in arbitrary unit) correspond to the mean 
intensity of the 2,500 laser shots composing each map (see text for background correction); sample Rat7V4 (B is a slice of sample A) is limited by two cookeite (+/- pyrophyllite) veins and contains en-echelon cookeite microveins in its centre; two LIBS profiles were performed between the cookeite veins (ablation zones visible); black squares highlight the ablation zones of the profile presented here; the horizontal position of sample Rat7V4 had to be checked and readjusted regularly due its large size, so this sample was analysed in several successive segments, which position can be slightly shifted; the second half of the profile was performed in a different analytical session: different room and laser conditions may be responsible for the higher variations in element intensity; host-rock profile is almost flat for most elements whereas $\mathrm{Li}$ shows a sudden increase in the pure cookeite veins; flat host-rock Li profiles suggest that the cookeite is evenly distributed in the host-rock between 2 successive cookeite veins; 5 linear profiles (3,000 juxtaposed $10 \mu \mathrm{m}$ diameter laser shots; shown by black arrows), performed across the en-echelon cookeite veins (contoured in black; C), show flat host-rock Li profiles with straight increase of Li in microveins; host-rock zones devoid of Li (and thus cookeite) are $<250 \mu \mathrm{m}(\mathrm{D})$; sample Rat7V1 (E: rock sample; F: thin section at same scale) is limited by two cookeite + pyrophyllite veins (only one visible on the thin section), but the veins were not analysed by LIBS; G- sample RatA1 is limited by a cookeite (+ chlorite in its centre) vein at one extremity, and en-echelon cookeite microveins at the other; $\mathrm{H}$ - sample RatA2 is limited by two cookeite veins, crosscut by a third oblique cookeite vein and contains multiple microveins; in both samples, intensity profiles are almost flat for most elements, including Li, suggesting an even distribution of cookeite in host-rocks between cookeite veins, in which Li shows a straight increase.

Figure 6. Schematic activity diagram showing the variation in $\mathrm{Li}$ and $\mathrm{Si}$ aqueous species activity as a result of cookeite solubility increase. Activity diagram plotting $\log \mathrm{a}\left(\mathrm{Li}^{+}\right) /$ 
$\mathrm{a}\left(\mathrm{H}^{+}\right)$vs. $\log \mathrm{a}\left(\mathrm{SiO}_{2}, \mathrm{aq}\right)$; grey and black lines represent the fluid saturation curves with respect to cookeite (Cook) and pyrophyllite (Prl) respectively. The black arrow represents the evolution of the equilibrium fluid concentration (black dots) for an increase in Cook solubility only, and shows that the activity of $\mathrm{Li}^{+}$will increase, whereas $\mathrm{a}\left(\mathrm{SiO}_{2}, \mathrm{aq}\right)$ is buffered by $\mathrm{Prl}$ solubility (and $\mathrm{Al}(\mathrm{OH})_{4}{ }^{-}$by Dsp solubility). Mineral solubility and corresponding activity of the equilibrium aqueous species were computed with the geochemical software ARXIM (developed by J. Moutte, Ecole des Mines de Saint-Etienne), using: the internally consistent thermodynamic database of Berman (1988) for mineral phases, completed by data for $\mathrm{Fe}$ chloritoid (B.E. Patrick and R.G. Berman, unpubl. data) and cookeite (Vidal and Goffé, 1991); the HKF equations (Helgeson et al., 1981) and thermodynamic data of Shock et al. (1997) for aqueous phases.

Figure 7. Schematic evolution of Li diffusion profiles in the host-rock between two cookeite-rich veins for A- reaction-limited transfer (frozen flat diffusion profiles) and Bdiffusion-limited transfer (bell-shape profiles flattened with time by complete mass transfer); evolution of the volume of initial cookeite transferred from host-rocks to veins by mass transfer with time; $\mathrm{t} 0<\mathrm{t} 1<\mathrm{t} 2<\mathrm{t} 3 \leq 1 \mathrm{Ma}$.

Figure 8. Synthesis diagram sketching the evolution of microstructures as well as modalities and potential driving forces for mass transport from host-rock to veins, along cookeite and pyrophyllite vein formation. A- During cookeite (Cook) vein formation, Li (+/- $\mathrm{Al}$ and $\mathrm{Si}$ ) diffuses from host-rock to veins along cookeite chemical potential gradients in the fluid, suggesting that the vein fluid interacted with the whole rock volume, i.e., the characteristic diffusion distance equals the half distance between two successive cookeite veins (i.e., a few $\mathrm{cm}$ ). Chemical potential gradients driving mass transfer could be either 
interfacial energy driven (Ostwald ripening) or stress-induced. B- Pyrophyllite (Prl) transfer to veins is obviously driven by pyrophyllite chemical potential gradients in the fluid between host-rock and pores. The shift from cookeite to pyrophyllite transfer remains unclear: if cookeite chemical potential gradients in the fluid were still active (case 1), cookeite transfer may have been interrupted by preferential pyrophyllite transfer (initiation of the retrograde path, see text). In this case, the modelled slow kinetic constants (associated to high diffusion coefficients) suggest the existence of fluid-poor micro-domains from which Li release into the diffusive fluid-filled network was limited. If cookeite chemical potential gradients vanished (case 2), only cookeite at equilibrium with the vein cookeite remains in the host-rock, i.e., mostly as euhedral fibrous microveins and pods. Ms: muscovite; Cld: chloritoid; Hem: hematite; Dsp: diaspore.

Figure 9. Activity diagrams showing the variation of cookeite, pyrophyllite and diaspore solubility for a pressure increase of $10 \mathrm{MPa}$ at $360{ }^{\circ} \mathrm{C}$. A- Activity diagram plotting log $\left[\mathrm{a}\left(\mathrm{Li}^{+}\right) / \mathrm{a}\left(\mathrm{H}^{+}\right)\right]$vs. $\log \mathrm{a}\left(\mathrm{SiO}_{2}, \mathrm{aq}\right)$; grey and black lines represent the fluid saturation curves with respect to cookeite (Cook) and pyrophyllite (Prl) respectively; B- Activity diagram plotting $\log \left[\mathrm{a} \mathrm{Al}(\mathrm{OH})_{4}{ }^{-} / \mathrm{a}(\mathrm{OH})^{-}\right]$vs. $\log \mathrm{a}\left(\mathrm{SiO}_{2}, \mathrm{aq}\right)$; grey and black lines represent the fluid saturation curves with respect to diaspore (Dsp) and pyrophyllite respectively.. Solid and dashed lines are equilibrium curves at 0.49 and $0.5 \mathrm{GPa}$, respectively. The black arrow thus represents the evolution of the equilibrium fluid concentration (black dots) for a pressure increase of $10 \mathrm{MPa}$ : Cook and Prl will be dissolved, while Dsp will rather crystallize. Mineral solubility and corresponding activity of the equilibrium aqueous species were computed as explained for Fig. 6 (see Appendix C for details), considering a fluid in equilibrium with the complete metabauxite mineral assemblage $($ diaspore + cookeite + pyrophyllite + chloritoid + muscovite + paragonite) 
Table 1: Characteristics of the selected spectroscopic emission lines and detection limits for chemical elements.

\begin{tabular}{|c|c|c|c|}
\hline Element & Wavelength (nm) & Line type $^{\text {a }}$ & Detection limit $^{\text {b }}$ \\
\hline $\mathrm{Li}$ & 670.78 & $\mathrm{I}-\mathrm{R}$ & $1-3 \mathrm{ppm}$ \\
\hline $\mathrm{Fe}$ & 382.78 & $\mathrm{I}$ & $1000 \mathrm{ppm}$ \\
\hline $\mathrm{Mg}$ & 383.82 & $\mathrm{I}$ & $1000 \mathrm{ppm}$ \\
\hline $\mathrm{Si}$ & 390.55 & $\mathrm{I}$ & $800 \mathrm{ppm}$ \\
\hline \multirow{2}{*}{$\mathrm{Al}$} & 394.40 & $\mathrm{I}-\mathrm{R}$ & $1 \mathrm{ppm}$ \\
\cline { 2 - 4 } & 396.15 & $\mathrm{I}-\mathrm{R}$ & $1 \mathrm{ppm}$ \\
\hline
\end{tabular}

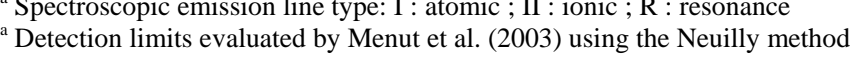

Table 2: Chemical analysis (wt\%) of host-rock samples from the western Vanoise metabauxites, for rocks both bearing and devoid of cookeite veins.

\begin{tabular}{|c|c|c|c|c|c|c|c|c|c|c|c|c|c|c|c|c|c|c|c|c|c|}
\hline & \multicolumn{12}{|c|}{ host-rocks (of rocks bearing cookeite veins) } & \multicolumn{9}{|c|}{ host-rocks (of rocks devoid of cookeite veins) } \\
\hline & Rat7V1 & Rat7V4 & RatA1 & RatA2 & RatA3 & Rat1-15 & Rat1 & Rat13 & RatE6 & RatE1 & RatE2 & mean & RatV10 & RatV11 & RatV4 & Rat9425M* & Rat9426M* & Rat6V1* & Rat9431* & Rat9432* & mean \\
\hline $\mathrm{SiO}_{2}$ & 22.18 & 19.57 & 19.55 & 30.36 & 18.54 & 16.99 & 18.41 & 19.14 & 11.35 & 14.02 & 21.87 & 19.27 & 10.03 & 15.17 & 26.78 & 24.9 & 26.33 & 22.10 & 25.54 & 25.49 & 22.04 \\
\hline $\mathrm{Al}_{2} \mathrm{O}_{3}$ & 47.01 & 47.17 & 49.87 & 38.74 & 44.64 & 49.93 & 46.24 & 45.58 & 52.19 & 47.85 & 40.26 & 46.32 & 55.07 & 51.85 & 44.49 & 51.99 & 49.15 & 43.94 & 51.27 & 49.91 & 49.71 \\
\hline $\mathrm{Fe}_{2} \mathrm{O}_{3}$ & 14.11 & 18.23 & 15.85 & 17.19 & 21.29 & 19.16 & 22.51 & 21.27 & 20.77 & 22.20 & 23.02 & 19.60 & 20.06 & 18.53 & 14.72 & 1.78 & 2.94 & 19.57 & 8.60 & 10.21 & 12.05 \\
\hline MnO & 0.03 & 0.04 & 0.04 & 0.02 & 0.13 & 0.05 & 0.04 & 0.08 & 0.05 & 0.04 & 0.06 & 0.05 & 0.06 & 0.04 & 0.04 & 0.08 & 0.09 & 0.09 & 0.10 & 0.12 & 0.08 \\
\hline MgO & 0.27 & 0.32 & 0.32 & 0.58 & 0.79 & 0.51 & \begin{tabular}{|l|}
0.41 \\
\end{tabular} & 0.67 & 0.37 & 0.42 & 0.59 & 0.48 & 0.38 & 0.26 & 0.63 & 0.53 & 0.65 & 0.51 & 0.61 & 0.76 & 0.54 \\
\hline $\mathrm{CaO}$ & - & - & - & 0.04 & - & 0.06 & - & - & - & - & - & 0.05 & - & - & 0.07 & 0.06 & 0.05 & - & - & - & 0.03 \\
\hline $\mathrm{Na}_{2} \mathrm{O}$ & - & - & - & 1.02 & 0.13 & 0.08 & \begin{tabular}{|l|}
0.30 \\
\end{tabular} & 0.08 & 0.11 & 0.13 & 0.16 & 0.25 & 0.08 & 0.15 & 0.97 & 0.08 & 0.09 & 0.14 & 0.08 & 0.07 & 0.21 \\
\hline $\mathbf{K}_{2} \mathbf{O}$ & 0.33 & 0.32 & 0.38 & 3.05 & 0.22 & 0.35 & \begin{tabular}{|l|}
0.62 \\
\end{tabular} & 0.50 & 0.18 & 0.34 & 0.48 & 0.62 & 0.13 & 0.24 & 1.68 & 0.30 & 0.24 & 0.35 & 0.38 & 0.24 & 0.45 \\
\hline $\mathbf{L i}_{2} \mathbf{O}$ & 0.13 & 0.18 & 0.15 & 0.39 & 0.19 & 0.15 & \begin{tabular}{|l|}
0.15 \\
\end{tabular} & 0.17 & 0.12 & 0.17 & 0.27 & 0.19 & 0.07 & 0.12 & 0.09 & 0.10 & 0.12 & 0.08 & 0.09 & 0.15 & 0.10 \\
\hline $\mathbf{T i O}_{2}$ & 3.80 & 3.03 & 3.31 & 1.32 & 4.90 & 3.14 & 1.64 & 2.78 & 4.40 & 4.71 & 5.20 & 3.48 & 3.81 & 3.38 & 1.64 & 2.65 & 2.60 & 3.97 & 3.08 & 2.86 & 3.00 \\
\hline $\mathbf{P}_{2} \mathbf{O}_{5}$ & 0.09 & 0.08 & 0.08 & 0.04 & 0.08 & 0.06 & 0.07 & 0.08 & 0.07 & 0.06 & 0.08 & 0.07 & 0.07 & 0.05 & 0.04 & 0.16 & 0.16 & 0.08 & 0.08 & 0.08 & 0.09 \\
\hline LOI & 10.83 & 9.72 & 9.61 & 7.03 & 8.10 & 9.94 & 8.70 & 8.50 & 10.20 & 9.82 & 7.58 & 9.09 & 10.35 & 9.80 & 8.71 & 11.56 & 11.56 & 8.48 & 9.35 & 9.21 & 9.88 \\
\hline Total & 98.64 & 98.47 & 98.99 & 99.37 & 98.81 & 100.26 & \begin{tabular}{|l|l|}
98.94 \\
\end{tabular} & 98.67 & 99.69 & \begin{tabular}{|c|}
99.58 \\
\end{tabular} & 99.30 & 99.16 & 100.04 & 99.45 & 99.77 & 94.189 & 93.98 & 99.30 & 99.17 & 99.09 & 98.12 \\
\hline
\end{tabular}

LOI: loss on ignition. Whole-rock chemical analyses (oxide weight \%)

* analyses from Verlaguet et al. (2011) 
Table 3: Cookeite distribution in veins vs host-rock, inferred from relative vein vs host-rock volumes and Li concentration in the host-rock.

\begin{tabular}{|c|c|c|c|c|c|c|c|c|c|c|c|c|c|c|}
\hline & Rat7V1 & Rat7V4* & RatA1 & RatA2* & RatA3 & Rat1-15* & Rat1* & RatE1 & RatE2* & Rat13* & RatE6 & mean & $\min$ & $\max$ \\
\hline wt $\% \mathrm{Li}_{2} \mathrm{O}$ in host-rock ${ }^{\mathrm{a}}$ & 0.13 & 0.18 & 0.15 & 0.39 & 0.19 & 0.15 & 0.15 & 0.17 & 0.27 & 0.17 & 0.12 & 0.19 & 0.12 & 0.39 \\
\hline modal vol\% of Cook in host-rock ${ }^{b}$ & 6 & 8 & 7 & 16 & 9 & 7 & 7 & 8 & 13 & 8 & 6 & 9 & 6 & 16 \\
\hline Vol (host-rock) / vol (vein) ${ }^{\mathrm{c}}$ & 10 & 16 & 9 & 16 & 11 & 18 & 9 & 10 & 11 & & & 12 & 9 & 18 \\
\hline vol\% Cook in veins ${ }^{\mathrm{d}}$ & 63 & 43 & 63 & 28 & 51 & 46 & 63 & 56 & 43 & & & 51 & 28 & 63 \\
\hline calc wt $\% \mathrm{Li}_{2} \mathrm{O}$ in bulk rock & 0.32 & 0.30 & 0.36 & 0.50 & 0.36 & 0.26 & 0.36 & 0.35 & 0.43 & & & 0.36 & 0.26 & 0.50 \\
\hline
\end{tabular}

from host-rock chemical analysis (Table 1)

${ }^{\mathbf{b}}$ modal amount of cookeite (vol\%) remaining in depleted host-rocks, calculated from the chemical analysis and the observed mineralogy, following the assumptions of Verlaguet et al. (2011)

' ratio of the host-rock volume versus cookeite vein volume calculated from the respective measured vein thickness / host-rock thickness between two successive cookeite veins (x $1 \mathrm{~cm}$ depth $\mathrm{x} 1 \mathrm{~cm}$ length); vein/hostrock geometry was difficult to infer precisely for some rocks that broke along vein planes during sampling

d degree of cookeite concentration in veins, calculated as the vol\% of the whole-rock cookeite that is concentrated in veins compared to that remaining in the host-rock

${ }^{e}$ calculated total amount of cookeite (wt\%) initially contained in bulk rocks before part of it was transferred to veins during metamorphism, inferred from the host-rock/vein geometry, Li $2 \mathrm{O}$ concentration in the host-

rock, chemical analysis of Vanoise cookeite ( $2.45 \mathrm{wt} \% \mathrm{Li}_{2} \mathrm{O}$; Vidal and Goffé, 1991), and rock density calculated from its modal composition

* host-rocks showing numerous pisoids and/or micrometric cookeite veins.

Table 4: Amount of minerals dissolved or crystallized in response to a pressure increase of $10 \mathrm{MPa}$ in Vanoise metabauxites and Oisans metamarls.

\begin{tabular}{|c|c|c|c|c|c|c|}
\hline Vanoise metabauxites & Dsp & Prl & Cook & Ms & $P g$ & Fe-Cld \\
\hline$V m\left(\mathrm{~cm}^{3} \cdot \mathrm{mol}^{-1}\right)^{\mathrm{a}}$ & 17.8 & 126.56 & 196.3 & 139.52 & 130.9 & 69.72 \\
\hline Min diss/cryst $\left(\mathrm{mol}^{2} / \mathrm{kg} \mathrm{H}_{2} \mathrm{O}\right)^{\mathrm{b}}$ & $1.2710^{-3}$ & $-2.6310^{-4}$ & $-1.1510^{-4}$ & $-7.8010^{-6}$ & $-4.9610^{-5}$ & $-1.8210^{-8}$ \\
\hline \multirow[t]{2}{*}{ Volume of min diss/cryst $\left(\mathrm{cm}^{3}\right)^{\mathrm{c}}$} & $2.2610^{-2}$ & $-3.3310^{-2}$ & $-2.2510^{-2}$ & $-1.0910^{-3}$ & $-6.4910^{-3}$ & $-1.2710^{-6}$ \\
\hline & $\mathrm{Si}$ & Al & $\mathbf{L i}$ & $\mathbf{K}$ & $\mathbf{N a}$ & $\mathrm{Fe}$ \\
\hline Aq. elem released $\left(\mathrm{mol} / \mathrm{kg} \mathrm{H} \mathrm{H}_{2} \mathrm{O}\right)^{\mathrm{d}}$ & $1.5710^{-3}$ & $7.3410^{-7}$ & $1.1510^{-4}$ & $7.8010^{-6}$ & $4.9610^{-5}$ & $1.8210^{-8}$ \\
\hline Oisans metamarls & Qtz & Prl & Cook & Ms & Calc & Chl \\
\hline$V m\left(\mathrm{~cm}^{3} \cdot \mathrm{mol}^{-1}\right)^{\mathrm{a}}$ & 22.24 & 126.56 & 196.3 & 139.52 & 36.93 & 221.47 \\
\hline Min diss/cryst $\left(\mathrm{mol}^{2} / \mathrm{kg} \mathrm{H}_{2} \mathrm{O}\right)^{\mathrm{b}}$ & $-2.6510^{-3}$ & $3.4910^{-4}$ & $-1.3510^{-4}$ & $-7.9010^{-6}$ & $-6.7910^{-5}$ & $-1.4910^{-9}$ \\
\hline \multirow[t]{2}{*}{ Volume of min diss/cryst $\left(\mathrm{cm}^{3}\right)^{\mathrm{c}}$} & $-5.8910^{-2}$ & $4.4210^{-2}$ & $-2.6410^{-2}$ & $-1.1010^{-3}$ & $-2.5110^{-3}$ & $-1.0410^{-7}$ \\
\hline & $\mathrm{Si}$ & $\mathbf{A l}$ & $\mathbf{L i}$ & $\mathbf{K}$ & $\mathrm{Ca}$ & Mg \\
\hline Aq. elem released $\left(\mathrm{mol} / \mathrm{kg} \mathrm{H}_{2} \mathrm{O}\right)^{d}$ & $1.6810^{-3}$ & $-1.3210^{-6}$ & $1.3510^{-4}$ & $7.9010^{-6}$ & $6.7910^{-5}$ & $1.4910^{-9}$ \\
\hline
\end{tabular}


Calculations performed with the geochemical software ARXIM (developed by J. Moutte, Ecole des Mines de Saint-Etienne), using: the internally consistent thermodynamic database of Berman (1988) for mineral phases, completed by data for Fe-chloritoid (B.E. Patrick and R.G. Berman, unpubl. data) and cookeite (Vidal and Goffé, 1991); the HKF equations (Helgeson et al., 1981) and thermodynamic data of Shock et al.

(1997) for aqueous phases. Calculations were carried out at $360^{\circ} \mathrm{C}, 0.49$ and $0.5 \mathrm{GPa}$ (although the peak metamorphic conditions are $360^{\circ} \mathrm{C}-1.2 \mathrm{GPa}$ ), as the validity of data for aqueous species is limited to $0.5 \mathrm{GPa}$.

Dsp: diaspore; Prl: pyrophyllite; Cook: cookeite; Ms: muscovite; Pg: paragonite; Cld: chloritoid; Qtz: quartz; Calc: calcite; Chl: chlorite (clinochlore).

${ }^{\mathrm{a}}$ Molar volume of minerals at $0.5 \mathrm{GPa}, 360^{\circ} \mathrm{C}$

${ }^{\mathbf{b}}$ Amount and ${ }^{\mathbf{c}}$ volume of minerals dissolved (-) or crystallised (+) for a pressure increase of $10 \mathrm{MPa}$ (from 0.49 and $0.5 \mathrm{GPa}$ ).

${ }^{\mathrm{d}}$ Amount of elements released in the fluid (as aqueous elements) for a similar pressure increase of $10 \mathrm{MPa}$, in moles $/ \mathrm{kg} \mathrm{H}_{2} \mathrm{O}$. 


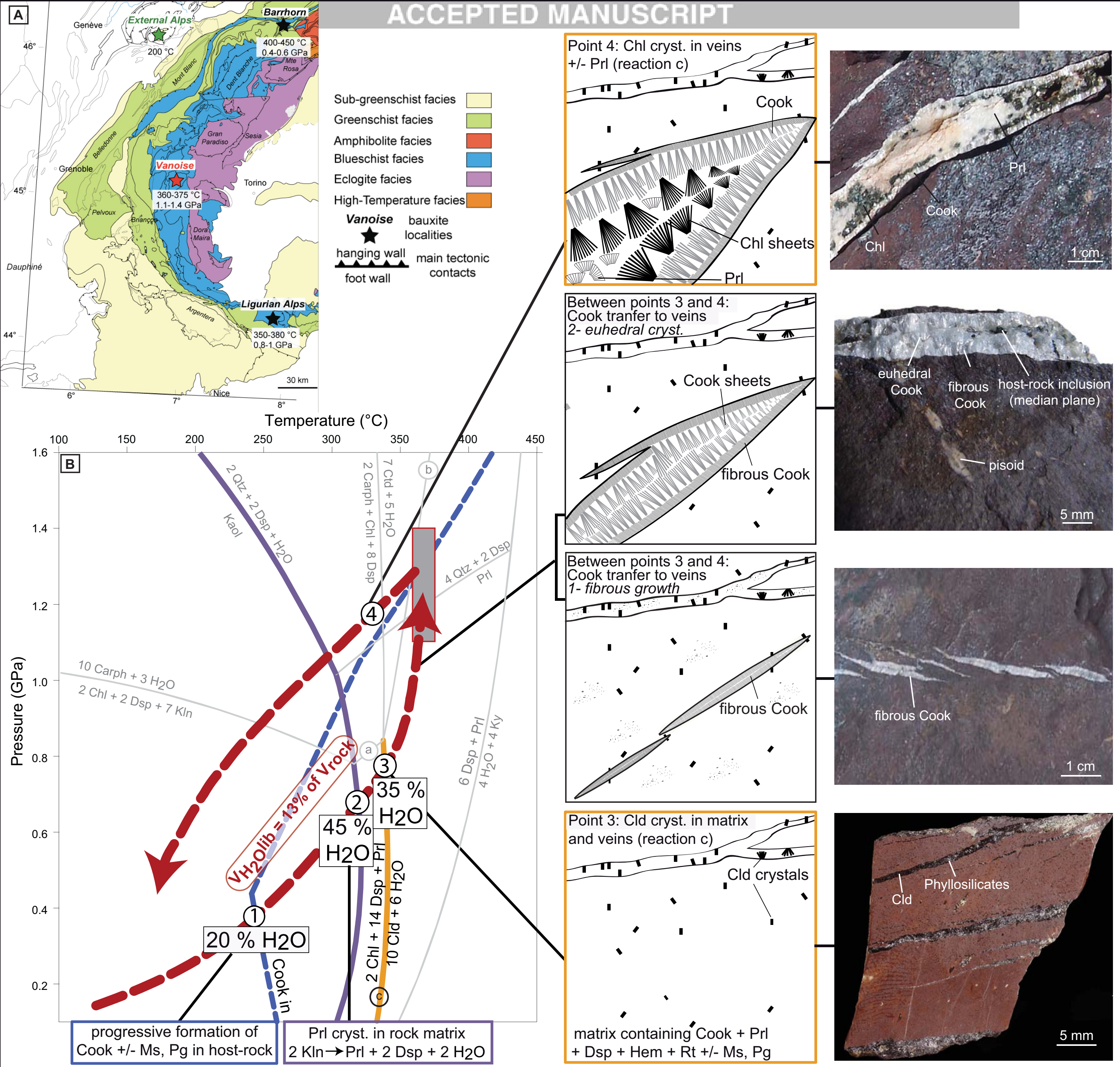




\section{$\mathrm{A}$}
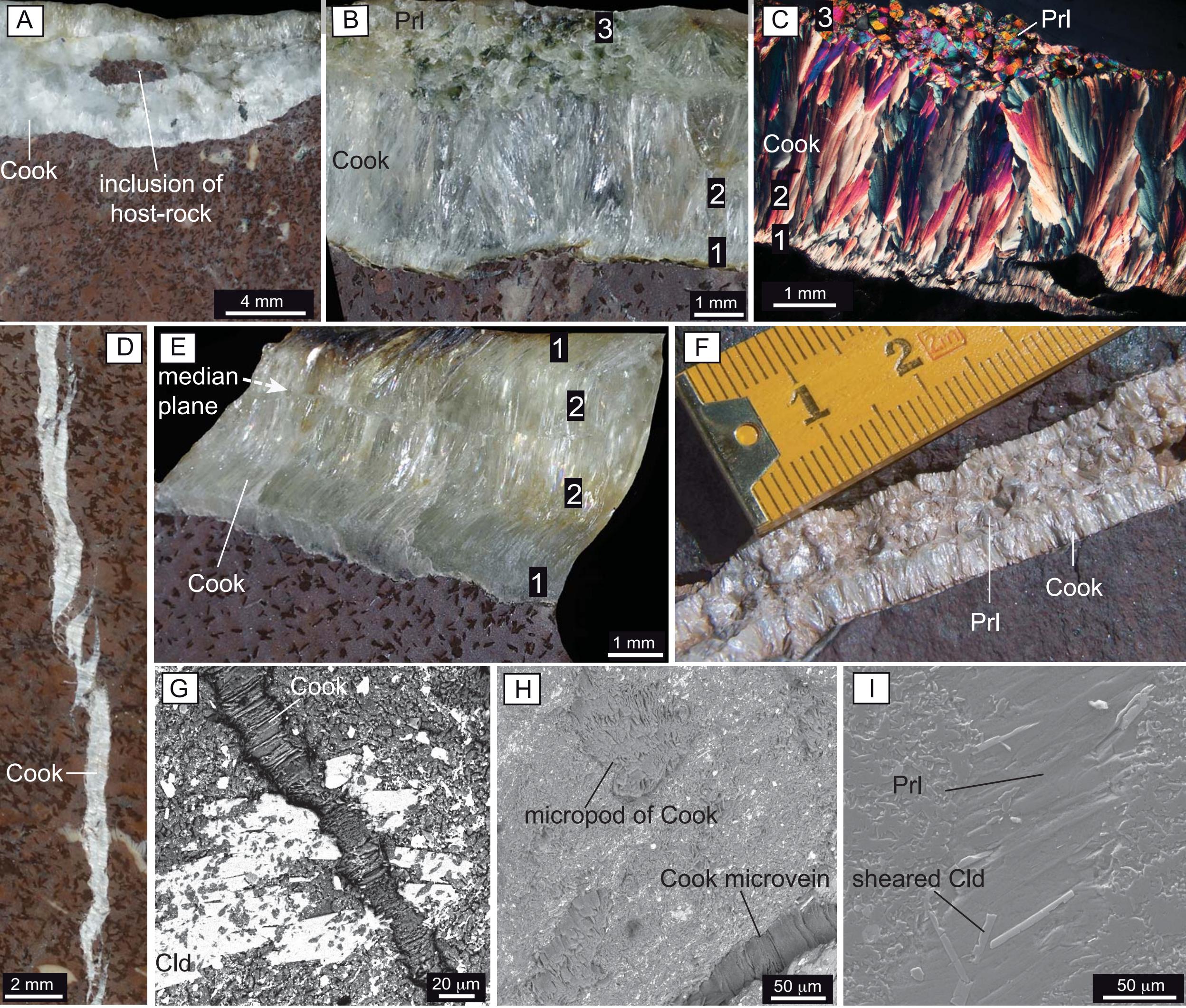

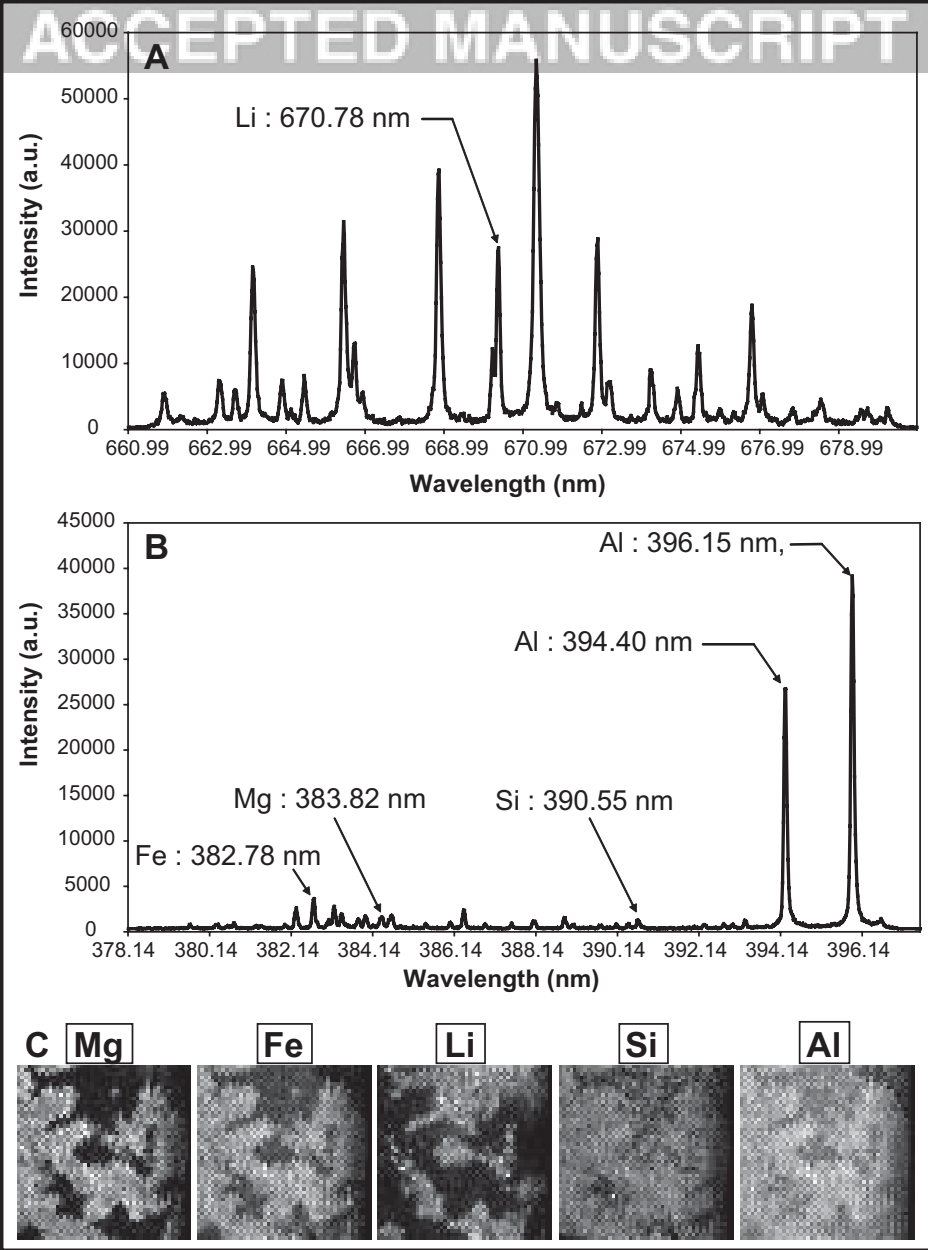


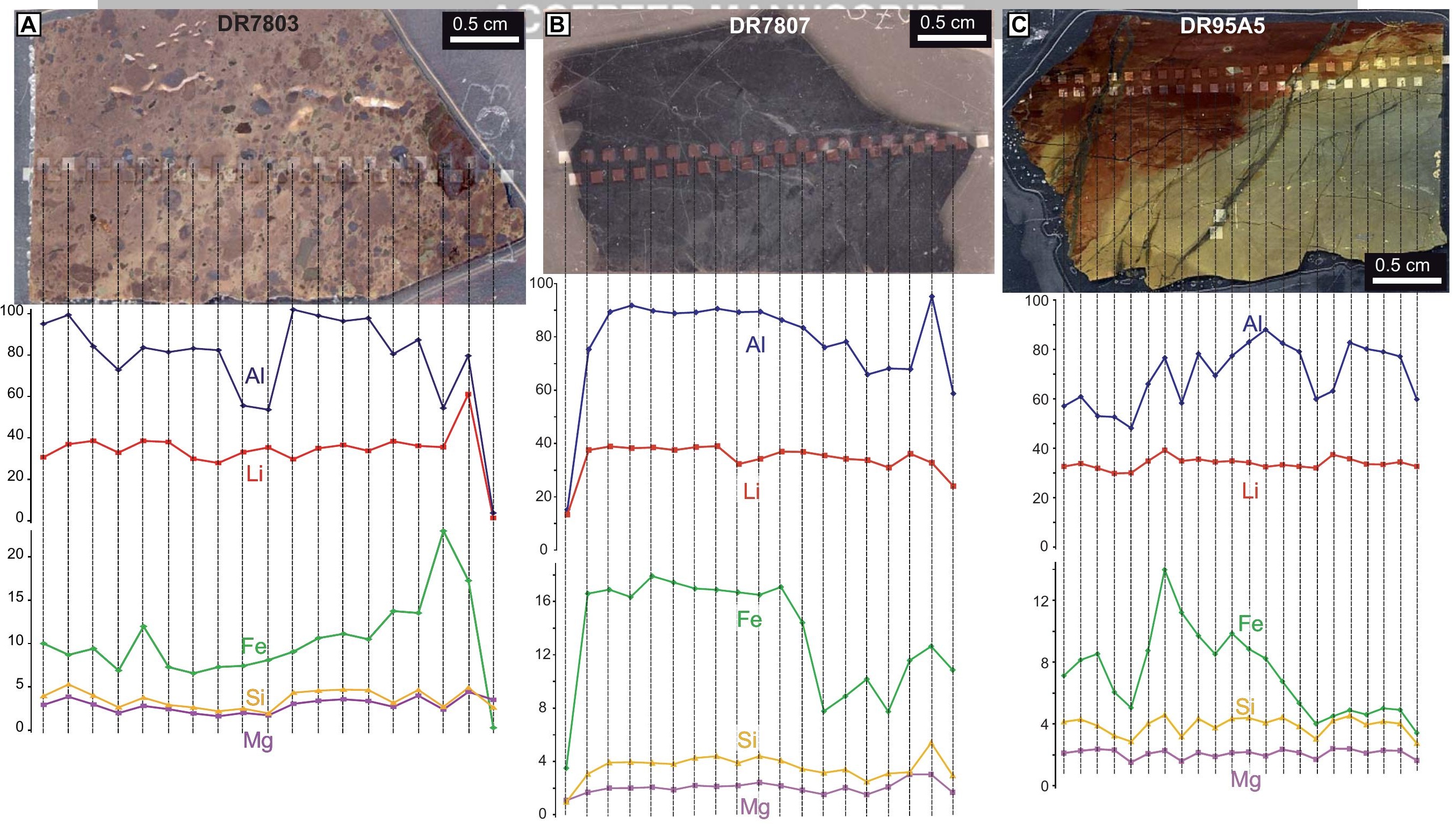




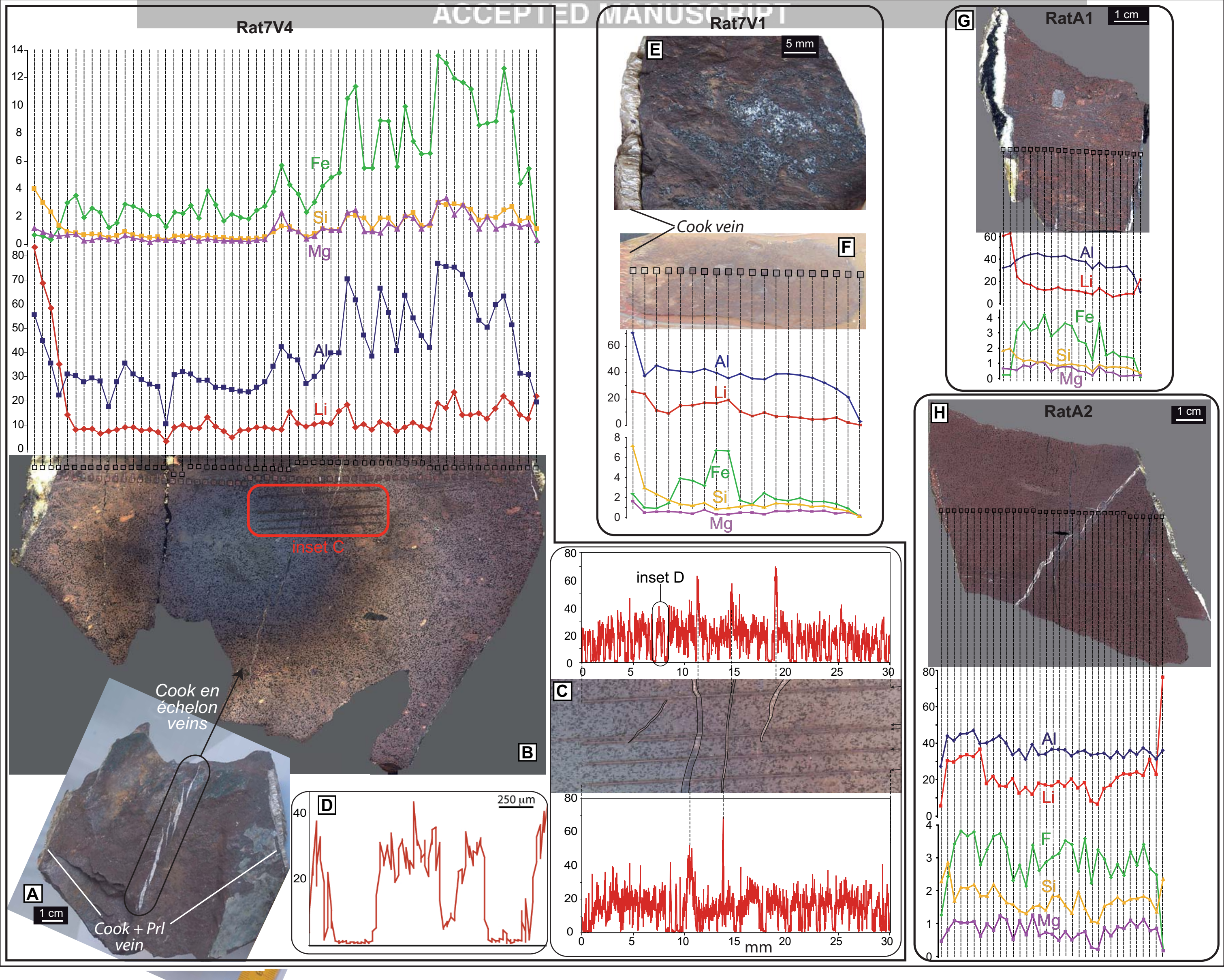


A- Frozen dissolution-limited Li profiles

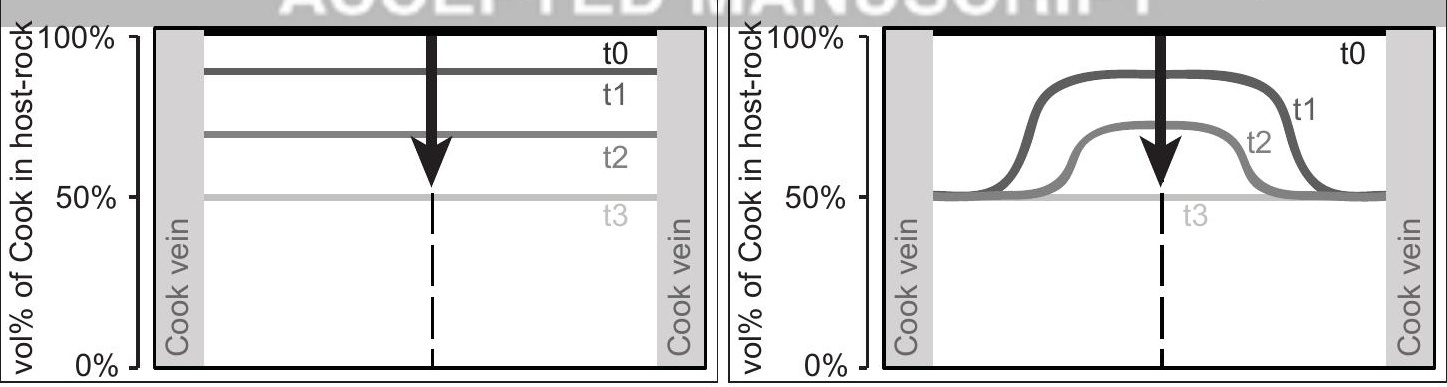


A-Cookeite vein formation

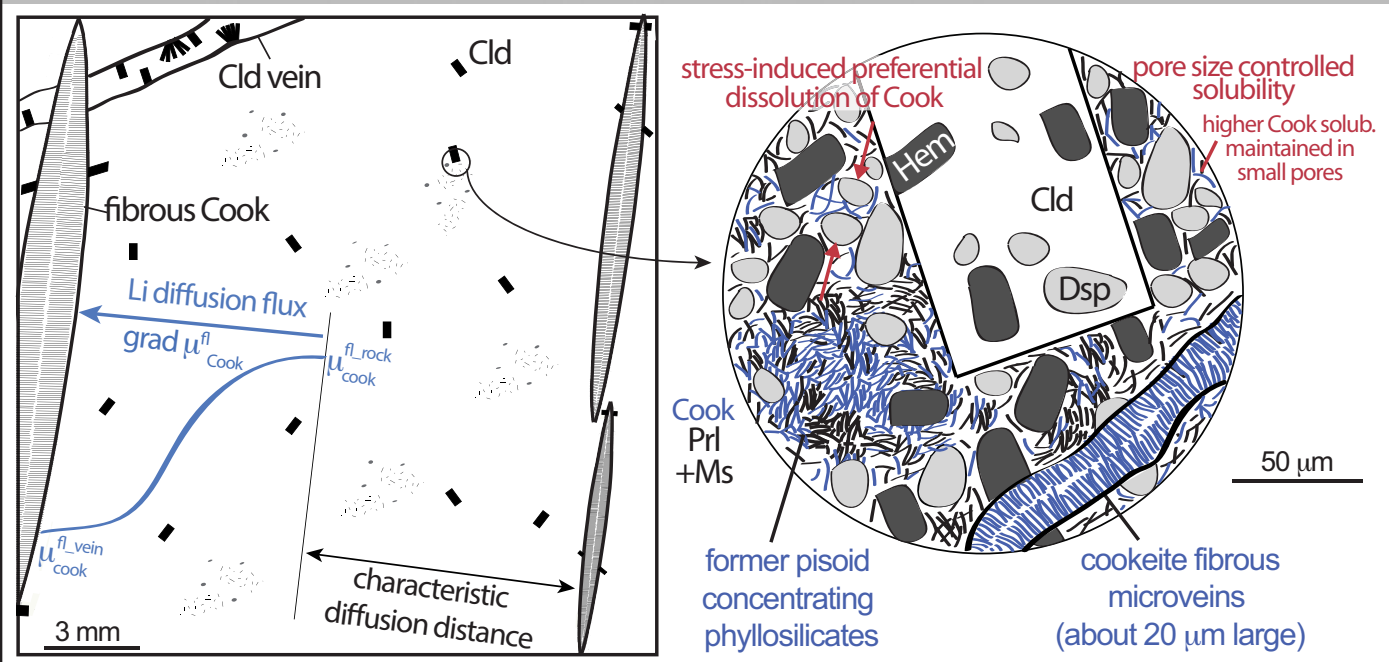

B-Pyrophyllite vein formation

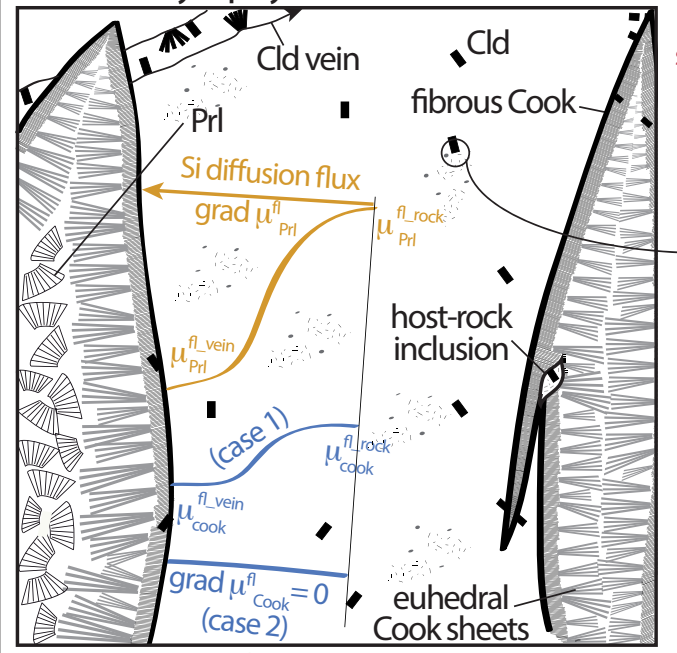

stress-induced preferential $\bigcirc$ pore size controlled

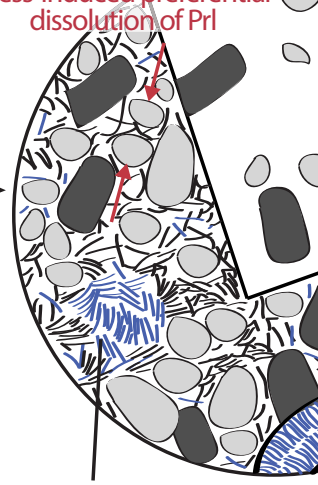

micropods (30-100 $\mu \mathrm{m})$ of well-stacked

Cook and Prl sheets

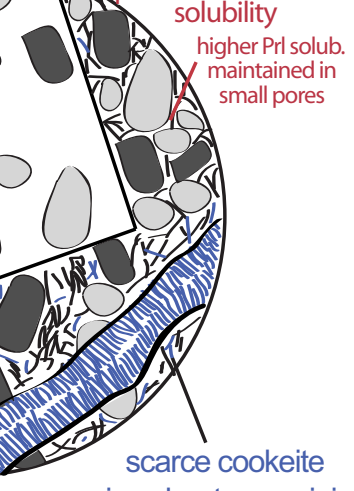

microsheets remaining in isolated microdomains within the host-rock 


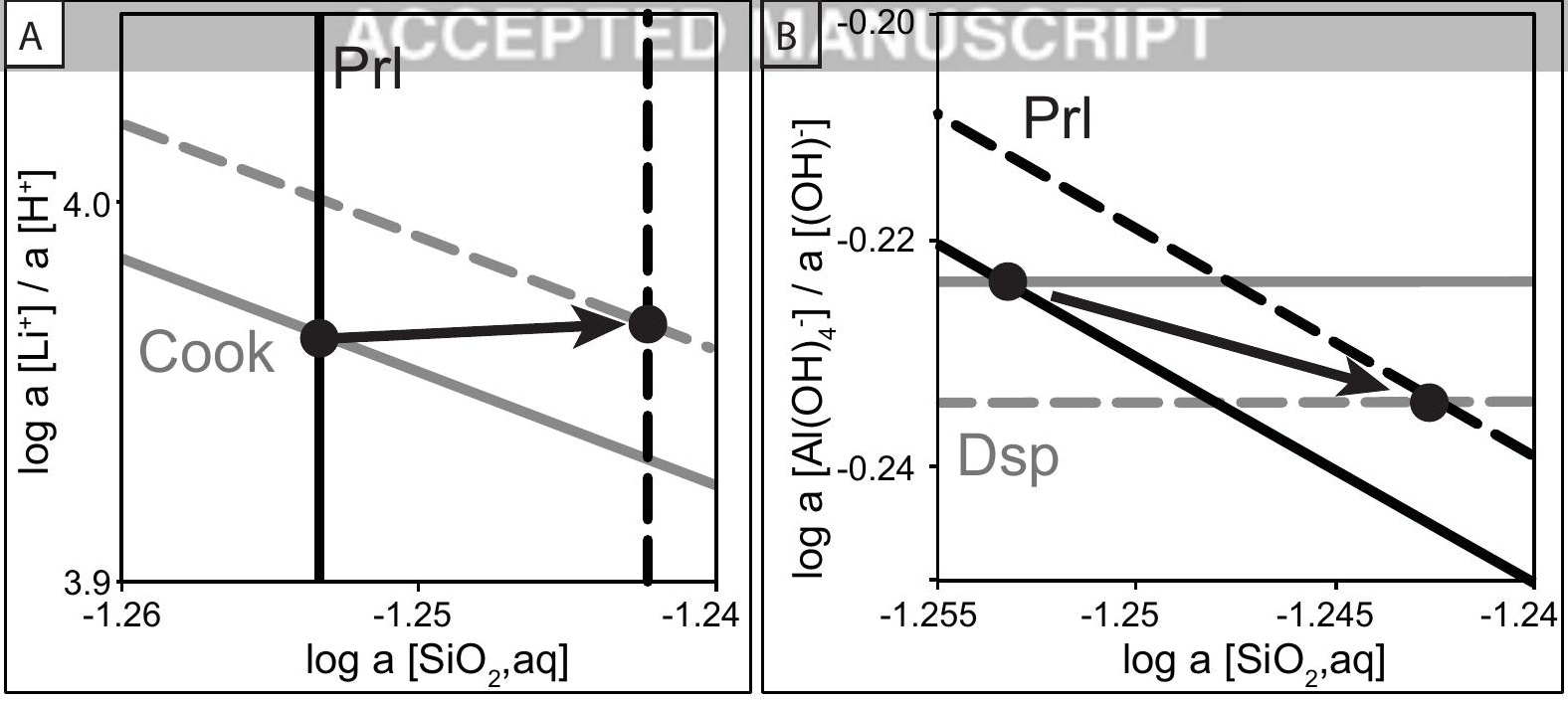

